\title{
Ferrofluids for heat transfer enhancement under an external magnetic field
}

\author{
N Gan Jia Gui a, C Stanley ${ }^{\text {a, N-T Nguyen }}{ }^{\text {b }, ~ G ~ R o s e n g a r t e n ~}{ }^{\text {a }}$ \\ a School of Engineering, Aerospace, Mechanical and Manufacturing, RMIT University, Melbourne, VIC 3053, \\ Australia \\ ${ }^{\text {b } Q u e e n s / a n d ~ M i c r o ~ a n d ~ N a n o t e c h n o l o g y ~ C e n t r e, ~ G r i f f i t h ~ U n i v e r s i t y, ~ B r i s b a n e, ~ Q L D ~ 4111, ~ A u s t r a l i a ~}$
}

\begin{abstract}
Overheating of power electronic devices has become a significant issue due to their continued miniaturization and increased heat flux that needs to be dissipated. Ferrofluids (magnetic nanofluids) have been shown to have higher thermal conductivity than their base aqueous or oil based fluids due to the solid magnetic nanoparticles that make up the ferrofluid. This allows higher convective heat transfer rates and, importantly, the ability to externally effect the flow using a magnetic field. In this paper, we focus on material characterization of ferrofluids and measurement of heat transfer rates for single-phase ferrofluidic forced convective flow in microchannels. We show that heat transfer properties of the flow are enhanced with the use of ferrofluids and that the material make-up of the ferrofluid affects these properties. In this paper, we argue that generally, convective heat transfer rates for ferrofluids are increased by increasing the solid volume concentration of magnetic particles ( 0.2-0.4\%). Interestingly, increasing magnetic flux was shown to decrease heat transfer enhancement. This was due to a reduction in the thermal conductivity of the bulk fluid caused by magnetic nanoparticles being drawn out of the isotropic mixture and becoming pinned to the channel wall in the region of strongest magnetic field. We show that there is good correlation between both theory and experimental visualization of this phenomenon.
\end{abstract}

Keywords: Ferrofluid, Magnetic Field, Heat Transfer, Thermal Conductivity, Microfluidic, Electronics Cooling

\section{Introduction}

Miniaturization and increased processing capabilities are the two technological trends of electronic devices, thus greater energy efficiency is desired whilst reducing their size. However, two major barriers to improve performance of such devices are the system interconnects and heat removal techniques [1]. System interconnect deals with integrating the front-side electronic device and the back-side cooling system, while heat dissipation techniques deal with enhancing heat transfer rates to the cooling system, or improving heat removal rates of the device [1]. One solution to this is to integrate cooling into the electronic chips. However, to obtain high heat fluxes, integrated liquid cooling typically utilises microchannels for increased surface area to transport fluid volume, which are characterised 
by very low Reynolds numbers (Re) and hence laminar flow. These characteristics limit the convective heat transfer coefficient to about $\mathrm{h} \leq 790 \mathrm{~W} / \mathrm{cm}^{2}$ [2]. One way to enhance heat transfer, is to increase the thermal conductivity of the working fluid. Nanofluids offer the ability to significantly enhance heat transfer by embedding nanoparticles of higher thermal conductivity than the carrier fluid. The high surface area to volume ratio inherent with nanoparticles provides excellent contact surface area for conductive heat transfer between the fluid and the solid particle, which acts to elevate the effective conductivity of the nanofluid mixture [3]. Ferrofluids are a subclass of nanofluids made of superparamagnetic nanoparticles that allow them to be easily manipulated by an external magnetic field [4]. Ferrofluids have been commonly used in audio loudspeakers to improve its audio response, increasing sound amplitude while reducing distortion. They have also been used in fluid seals for devices such as rotating shaft seals, where they allow for the almost complete elimination of frictional losses compared to traditional mechanical seals, or for high-speed computer disk drives to prevent the ingress of dust particles and impurities [4]. Therefore, manufacturing technologies of commercial ferrofluids are advanced, reliable, and cost effective.

Ferrofluids are essentially made up of three components - solid magnetic nanoparticles, a surfactant coating which helps prevent agglomeration of the particles, and a dispersion fluid medium [5]. Ensuring the particles remain dispersed in the carrier fluid is critical in achieving higher thermal conductivity compared to larger scaled suspensions [4]. The concentration by mass/volume, size and type of magnetic nanoparticle, surfactant, and dispersion medium, including the method of synthesis dictates the thermophysical properties of ferrofluids. These in turn influence the transport properties and thus, the convective heat transfer rates $[4,6$ 9].

An additional means to enhance heat transfer is introducing mixing in the microfluidic flow. Rapid mixing can be induced within microchannel flow either by active or passive methods $[10,11]$. Active methods require an external force such as electro-osmosis, magnetism, acoustics, thermocapillary, pulsating flow or mechanical stirring with moving parts [10]. Due to the magnetic nature of ferrofluids, rapid mixing can be easily produced by the application of an external magnetic field using permanent magnets, as has been demonstrated in this work.

In this paper, we aim to explain the behaviour of ferrofluids under the effect of an external magnetic field to enhance heat transfer properties of laminar microfluidic channel flow.

\subsection{Thermal Conductivity}

Table A1 in the appendix compiles past experimental results of ferrofluid thermal conductivity. Generally, the published results demonstrate that thermal conductivity increases with an increase in solid volume fraction $(\phi)$ and magnetic flux (B), and thermal conductivity decreases with an increase in temperature of the ferrofluid. Philip et al. [12, 13] found that enhancement in thermal conductivity compared to the base fluid occurs when solid volume fraction is more than $1.7 \%$. The maximum thermal conductivity enhancement observed was $300 \%$ when $\phi=6.3 \%$ at a magnetic flux of $8.2 \mathrm{mT}$, at $25^{\circ} \mathrm{C}$, where the magnetic field was applied parallel to the temperature gradient for a kerosene-based ferrofluid. The team observed that the maximum enhancement occurred when the value of magnetic flux 
matched the value of saturation magnetization of the ferrofluid. Past this value, thermal conductivity decreases with increasing magnetic flux. They attribute this to the cross-linking of the chains and subsequent distortion in the nematic-like order [12].

Gavili et al. [14] recorded a maximum thermal conductivity enhancement of $65.5 \%$ when $\phi=5 \%$ at a magnetic flux of $60 \mathrm{mT}$, at $25^{\circ} \mathrm{C}$, where the magnetic field was applied perpendicular to the measurement apparatus for a water-based ferrofluid. It must be noted that for both Gavili et al. [14] and Philip et al. [13] the test area used for measurements might be too small to record accurate results according to the manufacturer's specifications - a minimum of $15 \mathrm{~mm}$ of material parallel to the sensor in all directions is necessary for accurate measurements. Altan et al. $[15,16]$ observed that thermal conductivity decreases with increasing solid mass concentration (which translates to an increase in solid volume concentration). Jiang et al. [9] and Pastoriza-Gallego et al. [17] recorded an increase in thermal conductivity with an increase in temperature. However, Jiang et al. [9] prepared the water-based ferrofluid using thermal decomposition with phase transfer method as compared to co-precipitation adopted by other researchers who report a decrease in thermal conductivity with an increase in temperature, and Pastoriza-Gallego et al. [17] prepared ethylene glycol-based ferrofluids. As explained earlier, the difference in method of synthesis and dispersion fluid medium alters thermophysical characteristics of the ferrofluid. Hence, we cannot directly compare these two studies. Furthermore, this highlights the need for each ferrofluid type to have its properties carefully measured.

\subsection{Viscosity}

Minimising viscosity is important in minimising the pumping power required for the system.

Table A2 in the appendix compiles past experimental results for ferrofluid viscosity. Past experimental results have agreed that viscosity increases with an increasing solid volume concentration and magnetic flux strength, and viscosity decreases with increasing temperature [8, 18-21]. Li et al. [18] and Wang et al. [19] found that the rate of increase in viscosity is reduced with increasing solid volume concentration, magnetic flux strength and temperature. However, Li et al. [18] uses solid magnetic nanoparticles that are greater than $16 \mathrm{~nm}$ - the prescribed theoretical size limit for magnetite $\left(\mathrm{Fe}_{3} \mathrm{O}_{4}\right)$ nanoparticles to remain superparamagnetic [4].

As explained above, an increase in viscosity is unfavourable for the cost of pumping. However, while an increase in solid volume concentration and magnetic flux increases viscosity, and thus pressure drop, it also increases the thermal conductivity of the ferrofluid. Hence, an optimal solid volume concentration percentage and magnetic flux strength should be found to enhance heat transfer of the magnetofluidic flow whilst limiting the increase in viscosity; the aim being to increase the ratio of $N u / \Delta \mathrm{P}$.

\section{Materials and Experimental Methods}

\subsection{Material Characterization}

Commercial water-based ferrofluids (Domain Detection Kit, Ferrotec), containing fluid types EMG308, EMG408, EMG707, EMG708 and EMG807, were used to make diluted samples 
of $5 \%$ and $10 \%$ ferrofluid content for each EMG series, with de-ionized water (DIW). The initial properties given by the supplier are shown in Table 1 . This gives a volume ratio of ferrofluid:DIW as 0.05:0.95 for 5\% dilution, and 0.10:0.90 for $10 \%$ dilution. Thermophysical properties of the diluted samples were measured and compiled in Table 2.

Table 1: Supplier Given Properties - Domain Detection Kit

\begin{tabular}{llllll}
\hline Sample & \multicolumn{4}{l}{$\begin{array}{l}\text { Supplier Given Properties } \\
\end{array}$} & \multicolumn{2}{l}{ Components (\% by Volume) } & Density $\left(\mathrm{kg} / \mathrm{m}^{3}\right)$ & Sat Magnetization $(\mathrm{mT})$ \\
\cline { 2 - 5 } & Magnetite & Surfactant & Carrier & & \\
\hline EMG308 & $0.4-1.1$ & $0.5-1.5$ & $97.4-99.1$ & 1060 & 6.6 \\
\hline EMG408 & $0.4-1.1$ & $0.5-1.5$ & $97.4-99.1$ & 1070 & 6.6 \\
\hline EMG707 & $1-4$ & $7-27$ & $69-92$ & 1100 & 11 \\
\hline EMG708 & $1-4$ & $7-27$ & $69-92$ & 1080 & 6.6 \\
\hline EMG807 & $1-8$ & $6-60$ & $32-93$ & 1100 & 11 \\
\hline
\end{tabular}

Density of the diluted samples was measured at room temperature (RTP) $\left(\sim 22{ }^{\circ} \mathrm{C}\right)$ using a density bottle, also known as a pycnometer (Calibrated $25.102 \mathrm{~cm}^{3}$, BLAUBRAND ${ }^{\circledR}$ ). DIW was used as the calibration standard. Measurements were repeated three times and averaged.

Contact angle of the diluted ferrofluid samples on a flat polydimethylsiloxane (PDMS) surface (the material of the microchannel) was captured using a Canon EOS 700 digital singlelens reflex (DSLR) camera at RTP, then evaluated using ImageJ software.

\subsubsection{Particle Sizing}

It is well known that the size, shape, and composition of the magnetic nanoparticles strongly influence the thermophysical profile of the ferrofluid, and thus, their transport and flow properties. Since all the diluted samples contain $\mathrm{Fe}_{3} \mathrm{O}_{4}$ magnetic nanoparticles, the only variable is size. Depolarized dynamic light scattering (DDLS) and transmission electron microscopy (TEM) were employed to size the particles. Size distribution of the magnetic nanoparticles was obtained using DDLS, performed on an ALV-5022F spectrometer. Four measurements of 2-minute duration were performed, and the average of the data sets were taken. Morphology of the diluted samples were observed on a JEOL 1010 TEM (100 kV) equipped with a CCD camera (Orius SC600A, Gatan).

\subsubsection{Transport Properties}

Viscosity and thermal conductivity are dependent on the type and concentration of magnetic nanoparticles, and surfactant make-up of the ferrofluid. The type and strength of external magnetic field applied also affects these properties.

\section{Viscosity}

Kinematic viscosity of the diluted ferrofluid samples was measured at $25^{\circ} \mathrm{C}$ using a capillary viscometer (Micro-Ubbelohde 531 10, SCHOTT) along with a viscosity measuring system (ViscoSystem ${ }^{\circledR}$ AVS350, SCHOTT). This measurement was taken three times, and the final reading is the average of the three. DIW was used as the calibration standard. 
Grade N42 neodymium permanent magnets (40x15x8 mm, Aussie Magnets) were used to apply an external magnetic field to the ferrofluid. Magnetic flux was tuned by varying the offset distance between the capillary tube and the magnets.

\section{Thermal Conductivity}

Thermal conductivity of the diluted samples was measured at $25^{\circ} \mathrm{C}$ using the KD2 Pro Thermal Property Analyzer (Decagon Devices Inc.), which is based on the transient hot-wire method. The KS-1 single needle sensor with $1.3 \mathrm{~mm}$ diameter and $60 \mathrm{~mm}$ length was used. The fluid sample was held in a custom 3D printed aluminium box (See Figure 1) connected to a water bath (MB-5, Julabo), to keep the sample at a controllable constant temperature. The test sample containment area had a diameter of $31.3 \mathrm{~mm}$, and a height of $75 \mathrm{~mm}$ because a minimum of $15 \mathrm{~mm}$ of material parallel to the sensor in all directions is necessary for accurate measurements. Like the viscosity experiment, permanent magnets were used to apply an external magnetic field to the ferrofluids and magnetic flux was varied by varying the offset distance between the aluminium box and the magnets.

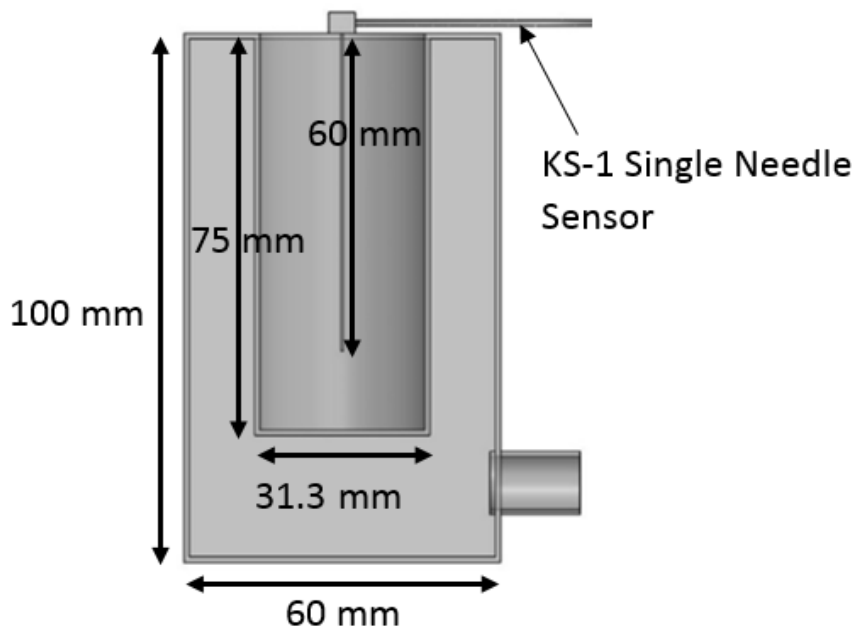

Figure 1: Custom 3D printed aluminium box dimensions

Table 2: Measured Properties of Diluted Ferrofluid Samples

\begin{tabular}{llllll}
\hline Sample & $\begin{array}{l}\text { Magnetite } \\
\text { Content } \\
\text { (\% by Volume) }\end{array}$ & $\begin{array}{l}\rho \\
\left(\mathrm{kg} / \mathrm{m}^{3}\right)\end{array}$ & $\begin{array}{l}\mu \\
(\mathrm{mPa} \cdot \mathrm{s})\end{array}$ & $\begin{array}{l}\text { Contact Angle } \\
\left({ }^{\circ}\right)\end{array}$ & $\begin{array}{l}\mathrm{K} \\
(\mathrm{W} /(\mathrm{m} \cdot \mathrm{K}))\end{array}$ \\
\hline EMG308 5\% & $0.02-0.055$ & 1006.0 & 1.025 & 90 & 0.646 \\
\hline EMG308 10\% & $0.04-0.11$ & 1008.1 & 1.046 & 110 & 0.644 \\
\hline EMG408 5\% & $0.02-0.055$ & 1004.6 & 1.029 & 113 & 0.636 \\
\hline EMG408 10\% & $0.04-0.11$ & 1006.2 & 1.040 & 114 & 0.626 \\
\hline EMG707 5\% & $0.05-0.2$ & 1012.9 & 1.078 & 80 & 0.642 \\
\hline EMG707 10\% & $0.1-0.4$ & 1021.0 & 1.103 & 106 & 0.645 \\
\hline EMG707 20\% & $0.2-0.8$ & 1022.5 & 1.129 & 80 & 0.655 \\
\hline EMG708 5\% & $0.05-0.2$ & 1005.9 & 1.029 & 109 & 0.682 \\
\hline EMG708 10\% & $0.1-0.4$ & 1009.8 & 1.060 & 105 & 0.684 \\
\hline
\end{tabular}




\begin{tabular}{llllll}
\hline EMG807 5\% & $0.05-0.4$ & 1006.7 & 1.040 & 100 & 0.644 \\
\hline EMG807 10\% & $0.1-0.8$ & 1009.7 & 1.050 & 84 & 0.651 \\
\hline DIW & - & 1000.0 & 1.000 & 115 & 0.610 \\
\hline
\end{tabular}

\subsection{Microchannel Fabrication}

To fabricate the microchannel, we adopted the method proposed by Saggiomo and Velders [22]. The design of the sacrificial microchannel mould (See Figure 2) was first 3D printed out in acrylonitrile butadiene styrene (ABS) with a layer thickness of $0.254 \mathrm{~mm}$. The microchannel mould was then vapour smoothed using acetone. Following this process, optical profiling was performed using the Olympus LEXT OLS4100 3D Measuring Laser Microscope to obtain both 2D (planar) and 3D (areal) surface roughness of the untreated and treated microchannel sacrificial moulds. Results indicated that the treated sacrificial moulds were about four times smoother than the untreated moulds (Refer to Table 3 ) and that the cross section became circular.

The bottom surface of the sacrificial mould, which was in direct contact with the rough support structure during the 3D printing process, decreased in roughness by a factor of 2-4 after treatment. However, the top surface, free from contact, becomes about 0.5-0.8 times rougher after treatment. This was due to the arbitrary vapour smoothing process. Overall, it was observed that surface roughness was improved after performing vapour smoothing with acetone with an approximate roughness to channel diameter ratio of 1/100.

A nichrome heater coil (wire gauge 28, JayCar) was carefully wrapped around the treated sacrificial mould over a section of the straight length (See Figure 2). Thermocouples were positioned near the microchannel walls using additional scarification ABS stems held perpendicular to the microchannel with an ABS guide structure (thermocouple adapter). Degassed PDMS at a mixture ratio of 10:1 was then poured into the pre-prepared glass mould over the sacrificial mould. The PDMS was left to cure in the oven at $75^{\circ} \mathrm{C}$ for $2-3$ hours. The thermocouple adapter and PDMS mould was removed, and the desired cured thermocoupleembedded microchannel PDMS was soaked in acetone for at least 48 hours to allow the acetone to soften the sacrificial mould. Acetone was then pushed through the inlet/outlet ports of the PDMS mould using a needleless syringe until all the sacrificial mould was fully dissolved and flushed out, creating a cavity. Finally, DIW was flushed through the cavity to clear any remaining solid particles, producing the desired microchannel (See Figure 3).

Table 3: Surface Roughness Results

\begin{tabular}{lllll}
\hline Sample & \multicolumn{2}{l}{ 2D Surface Roughness $(\boldsymbol{\mu m})$} & \multicolumn{2}{l}{ 3D Surface Roughness $(\boldsymbol{\mu m})$} \\
\cline { 2 - 5 } & Top & Bottom & Top & Bottom \\
\hline Sample 1 & 8.12 & 33.35 & 9.02 & 47.53 \\
\hline Sample 2 & 9.04 & 28.48 & 7.41 & 36.31 \\
\hline Sample 3 & 10.32 & 11.82 & 13.97 & 15.52 \\
\hline Sample 4 & 5.43 & 10.09 & 15.29 & 14.26 \\
\hline
\end{tabular}




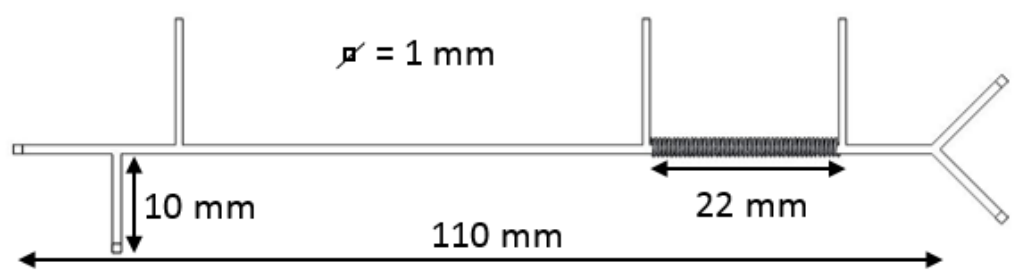

Figure 2: Microchannel sacrificial mould dimensions

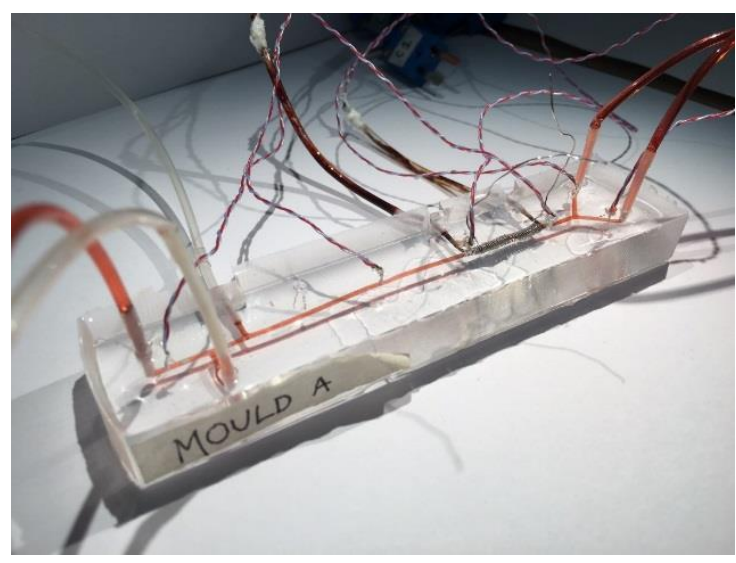

Figure 3: 3D casted PDMS microchannel with embedded nichrome heater

\subsection{Single Phase Flow Heat Transfer}

Eight T-type thermocouples (Teflon-insulated twisted pair solid 1/0.2 $\mathrm{mm}$ ) were embedded in the PDMS; two thermocouples embedded into the microchannel flow - one at the inlet heated area, and the other at the outlet heated area (See Figure 4). The other six thermocouples were along the microchannel length (See Figure 4a). Small diameter thermocouple wires were used to minimise conduction losses. Temperatures were recorded using a temperature data logger (TC-08, Pico Technology). The temperature measurement system was calibrated against a traceable platinum resistance thermometer (PRT) (P795, Dostmann).

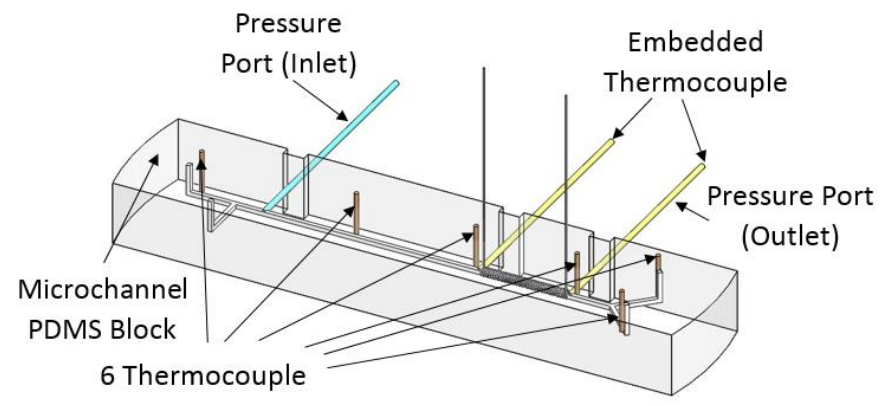

(a)

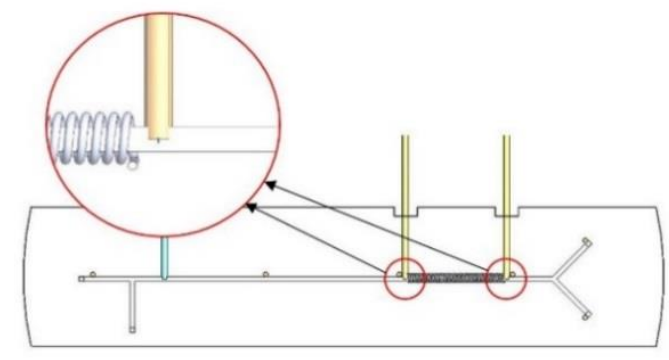

(b)

Figure 4: Embedded thermocouples in microchannel flow 


\subsubsection{Nusselt Number Calculation}

Nusselt number, $\mathrm{Nu}$, is expressed as

$$
N u=\frac{\mathrm{hD}_{\mathrm{h}}}{\mathrm{K}}
$$

where $D_{h}$ represents the hydraulic diameter, and $\mathrm{K}$ is the thermal conductivity of the fluid. The average convective heat transfer coefficient of the flow, $h$, is expressed as

$$
h=\frac{q_{f}}{\left(T_{w, \text { avg }}-T_{f, \text { avg }}\right)}
$$

where $q_{f}$ is the heat flux in $W / m^{2}, T_{w, a v g}$ is the average wall temperature difference $\left(T_{w, \text { out }}+\right.$ $\left.T_{\text {win }}\right) / 2$ and $T_{\text {avg }}$ is the average fluid temperature difference $\left(T_{\text {out }}+T_{\text {in }}\right) / 2$ across the heater. Here, $\mathrm{q}_{\mathrm{f}}$ can be calculated as

$$
\mathrm{q}_{\mathrm{f}}=\frac{\dot{\mathrm{Q} \rho c_{\mathrm{p}}}\left(\mathrm{T}_{\text {out }}-\mathrm{T}_{\text {in }}\right)}{\mathrm{A}}
$$

where $\dot{Q}$ is the volumetric flow rate, $\rho$ is density of the fluid, $c_{p}$ is the specific heat capacity of the fluid, $\left(T_{\text {out }}-T_{\text {in }}\right)$ is the average fluid temperature difference, and $A$ is the area in contact with the fluid.

As the solid volume fraction of magnetic nanoparticles is estimated to have an average of $0.03-0.4 \%$ depending on the sample, and $c_{p}$ for ferrofluid was assumed to have the same value as the carrier fluid (DIW).

\subsection{Flow Visualization}

Flow visualization was conducted for EMG707 20\% mixed with a fluorescein solution (Rhodamine 123:Ethanol = $2 \mathrm{mg}: 10 \mathrm{~mL}$ ) with a volume ratio of 5:1. Magnetic flux strength of $200 \mathrm{mT}$ perpendicular to the direction of flow was provided by grade N42 cuboid permanent magnet(s) with a base, width, and height of $3.2 \mathrm{~mm}$ (B222, K\&J Magnetics Inc.). A PDMS microfluidic chip fabricated using soft lithography bonded onto a $1 \mathrm{~mm}$ thick microscope glass slide (Prosciteh) with a channel width of $500 \mu \mathrm{m}$ and height of $200 \mu \mathrm{m}$ was used. Magnetic particle build-up was visualized using confocal microscopy (Eclipse Ti, Nikon). Single-phase ferrofluid flow was introduced to the microfluidic chip using a precision syringe pump (PHD ULTRA $^{\mathrm{TM}}$, Harvard Apparatus) via a gastight glass syringe (50 mL luer lock, SGE Analytical Science).

\subsection{Experimental Uncertainty Analysis}

Uncertainty estimations of measured parameters are based on the method outlined in Coleman \& Steele [23], using the examples shown in Stanley [24] as a guideline. The estimated uncertainty for Nusselt number determination is $39 \%$ which comprised of a bias (systematic) error and a precision (random) error [24]. 


\section{Results}

\subsection{Material Characterization}

\subsubsection{Particle Sizing}

\section{Depolarized Dynamic Light Scattering (DDLS)}

As the undiluted ferrofluid comes from the same stock, only $5 \%$ dilution ferrofluid samples were used for DDLS and TEM.

For DDLS, due to the opaqueness of the diluted ferrofluid samples, it was necessary to further dilute the samples to prevent the scattering of light. A dilution factor of 500 with DIW was performed on the $5 \%$ dilution ferrofluid samples. Intensity weighted graphs represents the amount of light intensity absorbed by the particles (See Figure 5 ). The larger the particle size, the more intensity it absorbs, thus, showing a higher peak. However, if a smaller sized particle can be observed compared to a larger particle, it means that there should be a lot of smaller particles observed in comparison to the larger particles. Number weighted graphs represents the predicted concentration of particles in the solution (See Figure 6). As seen in all measured samples, the number weighted graphs indicate that most of the sample is made up of smaller particles compared to larger ones. The reliability of these results was verified by performing TEM on the samples.

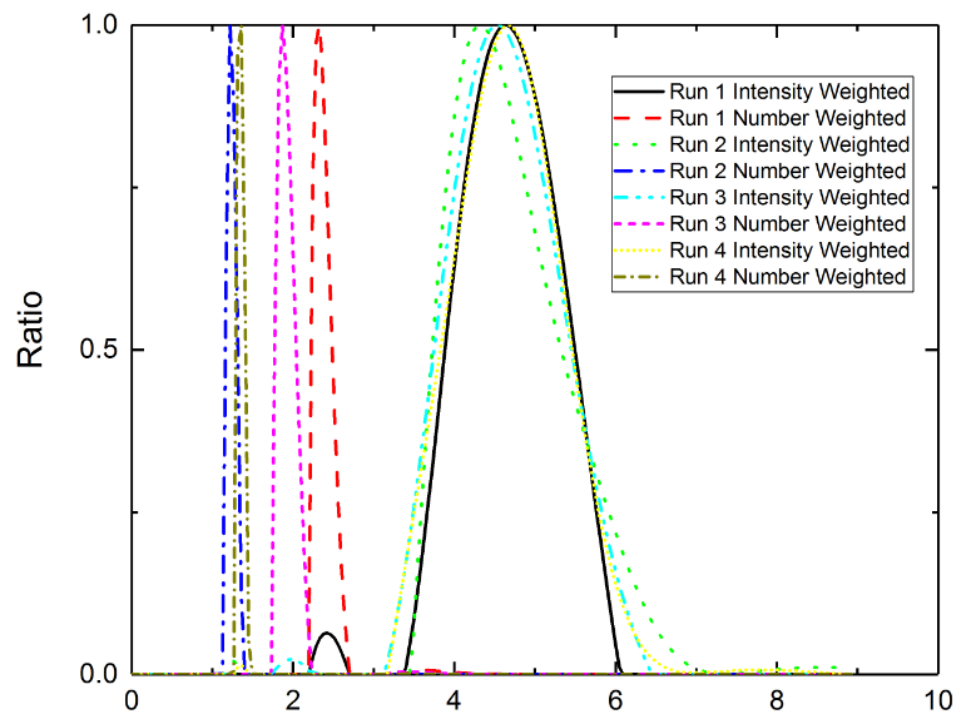

Figure 5: DDLS results for EMG707 ferrofluid - number weighted vs intensity weighted graphs

Table 3: Summary of DDLS Measurement Results

\begin{tabular}{lllllll}
\hline Sample & \multicolumn{9}{l}{ Particle Size (nm) } \\
\cline { 2 - 7 } & Run 1 & Run 2 & Run 3 & Run 4 & Avg & Max \\
\hline EMG308 & 2.13 & 4.07 & 8.17 & 8.56 & 5.73 & 46 \\
\hline EMG408 & 2.81 & 4.9 & 7.11 & 7.11 & 5.48 & 55 \\
\hline
\end{tabular}




\begin{tabular}{lllllll}
\hline EMG707 & 3.38 & 3.89 & 6.48 & 10.3 & 6.01 & 110 \\
\hline EMG708 & 4.26 & 6.19 & 8.18 & 8.18 & 6.70 & 121 \\
\hline EMG807 & 3.89 & 3.89 & 5.64 & 8.96 & 5.60 & 80 \\
\hline
\end{tabular}

\section{Transmission Electron Microscopy (TEM)}

From TEM, it was observed that the ferrofluids were fabricated using the co-precipitation method, reflected by the polydisperse magnetic nanoparticles [25]. The particle sizes obtained from TEM are slightly larger than those obtained from DDLS (See Figure 6). This is due to the evaporation under ambient atmosphere of the solution during sample preparation, where the nanoparticles are deposited onto strong carbon grids (GSCu200C-50), spurring the nanoparticles towards further aggregation due to the elevating free energy at the grain boundary [9]. However, it can be concluded that the number weighted graphs are reliable when compared to the TEM results (Refer to Table 3 and 4).

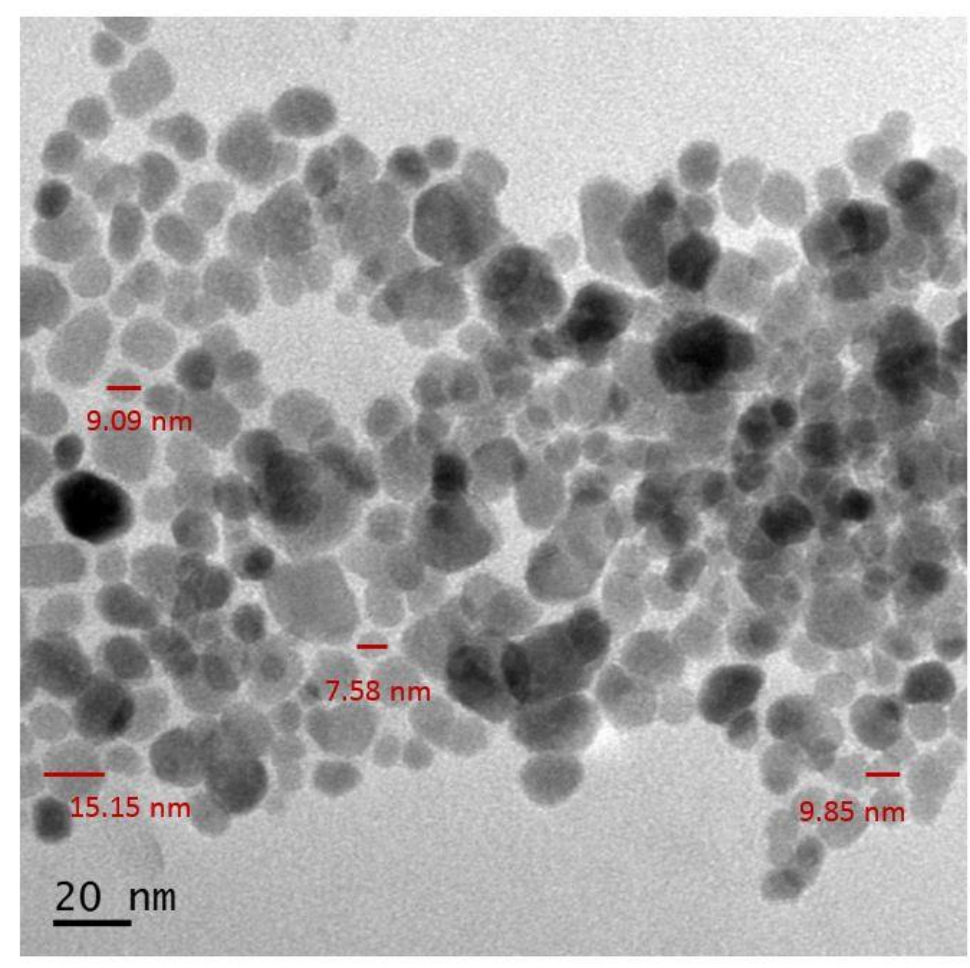

Figure 6: EMG807 TEM results

Table 4: Summary of TEM Results

\begin{tabular}{llllll}
\hline Sample & \multicolumn{6}{l}{ Measured Particle Size (nm) } \\
& Reading 1 & Reading 2 & Reading 3 & Reading 4 & Avg \\
\hline EMG308 & 6.93 & 7.73 & 8.64 & 13.64 & 9.23 \\
\hline EMG408 & 7.58 & 9.09 & 11.36 & 15.15 & 10.80 \\
\hline EMG707 & 4.51 & 6.77 & 9.77 & 15.04 & 9.02 \\
\hline EMG708 & 7.58 & 11.36 & 13.64 & 16.67 & 12.31 \\
\hline EMG807 & 7.58 & 9.09 & 9.85 & 15.15 & 10.42 \\
\hline
\end{tabular}




\subsubsection{Transport Properties}

\section{Viscosity}

It was observed that viscosity increases linearly with density (See Figure 7), and that both viscosity and density of the diluted ferrofluid samples are greater than that of the base fluid - DIW. The magnetic nanoparticles are considerably denser than the base fluid $\left(\rho_{\mathrm{Fe} 304}=\right.$ $5170.0 \mathrm{~kg} / \mathrm{m}^{3}$ ). It was also observed that viscosity increases linearly with magnetic flux (See Figure 8). The largest increase in viscosity is about 5\% for EMG308 10\% under a magnetic flux of $50 \mathrm{mT}$ compared to $0 \mathrm{mT}$ at RTP $\left(\sim 22^{\circ} \mathrm{C}\right)$. The increase in viscosity can be attributed to the alignment and clustering of magnetic nanoparticles in the direction of the applied magnetic field, which is perpendicular to the flow. These chains increase the resistance to the flow, thereby increasing viscosity. This is consistent with previous studies [8, 18-21].

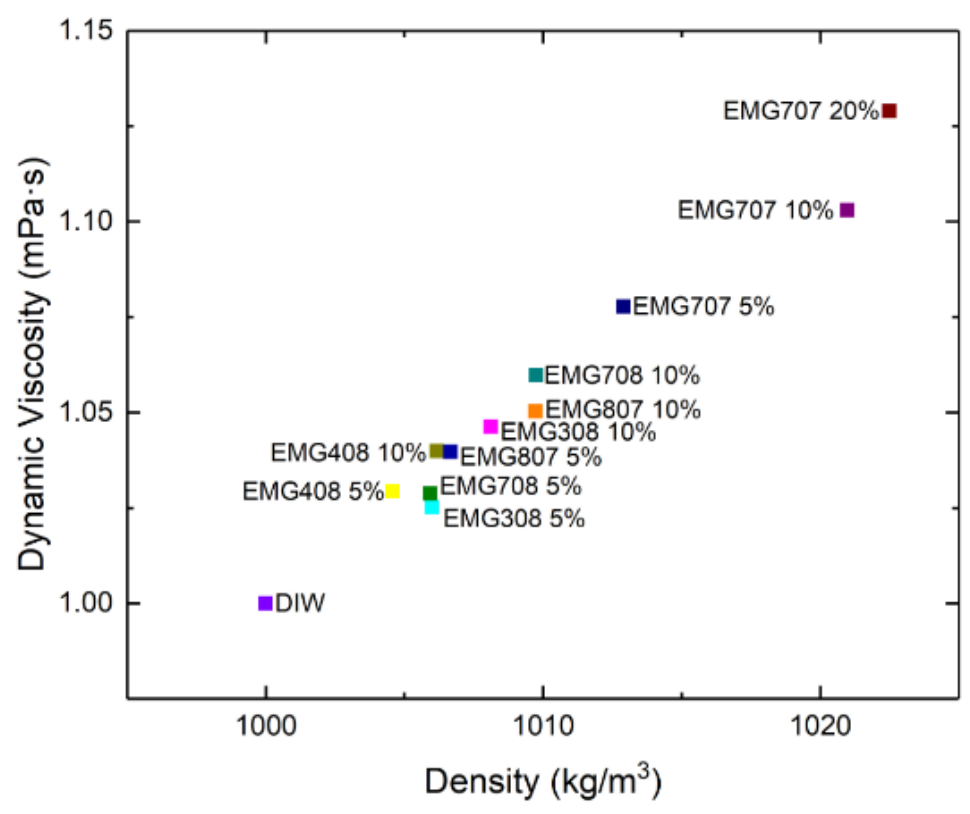

Figure 7: Dynamic viscosity vs density of diluted commercial ferrofluid solutions @ RTP 


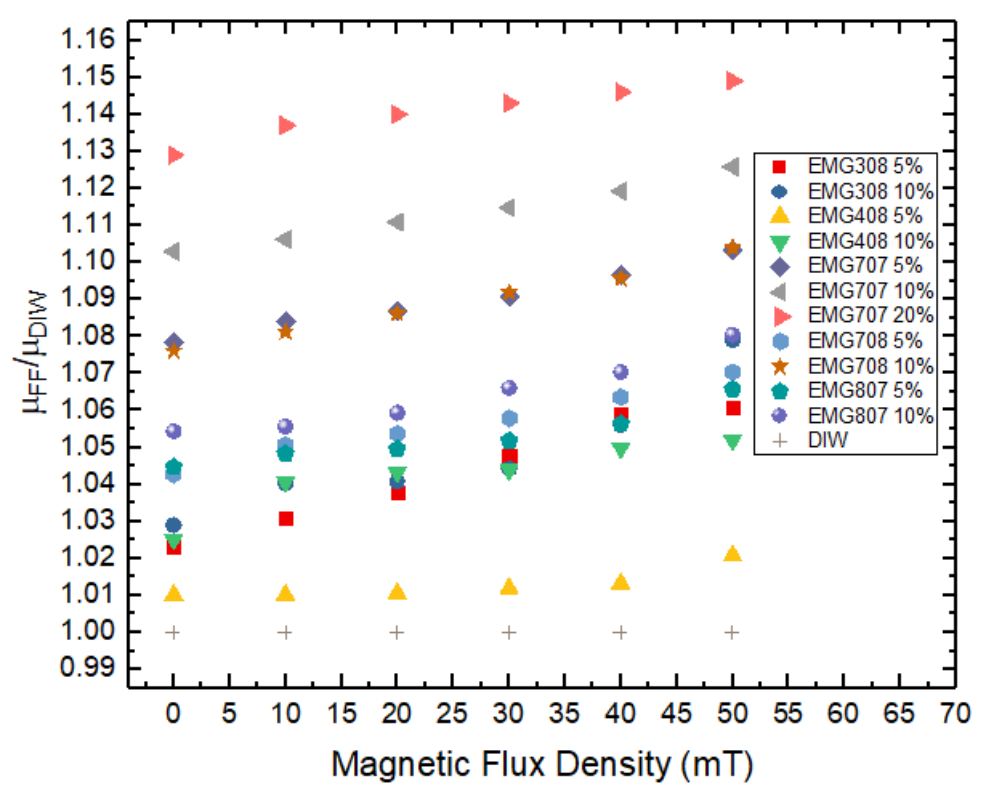

Figure 8: Viscosity experimental results with magnetic field @ RTP

\section{Thermal Conductivity}

Thermal conductivity measurements show that all the diluted ferrofluid samples have a slightly higher thermal conductivity value at $25^{\circ} \mathrm{C}$ compared to DIW (See Figure 9).

The thermal conductivity increases exponentially with the application of an external magnetic field (See Figure 10). The highest enhancement is about 100\% for EMG708 10\% compared to DIW. The increment of thermal conductivity can be attributed to the alignment of the magnetic nanoparticles with the application of an external magnetic field $[26,27]$. Due to the superparamagnetic nature of the magnetic nanoparticles, the solid nanoparticles will align themselves in the direction of the applied magnetic field. These solid nanoparticles cluster to form more efficient conduction pathways which enhances conductive heat transfer. 


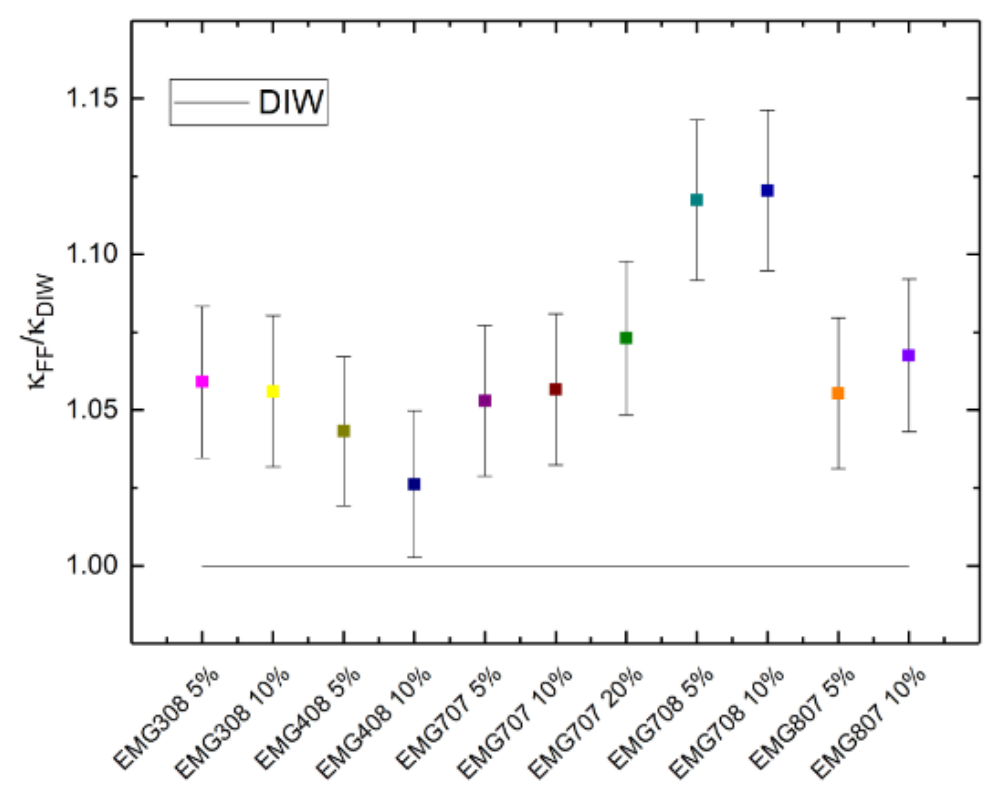

Figure 9: Measured thermal conductivity ratio (KFF/KDIw) without magnetic field @ $25^{\circ} \mathrm{C}$

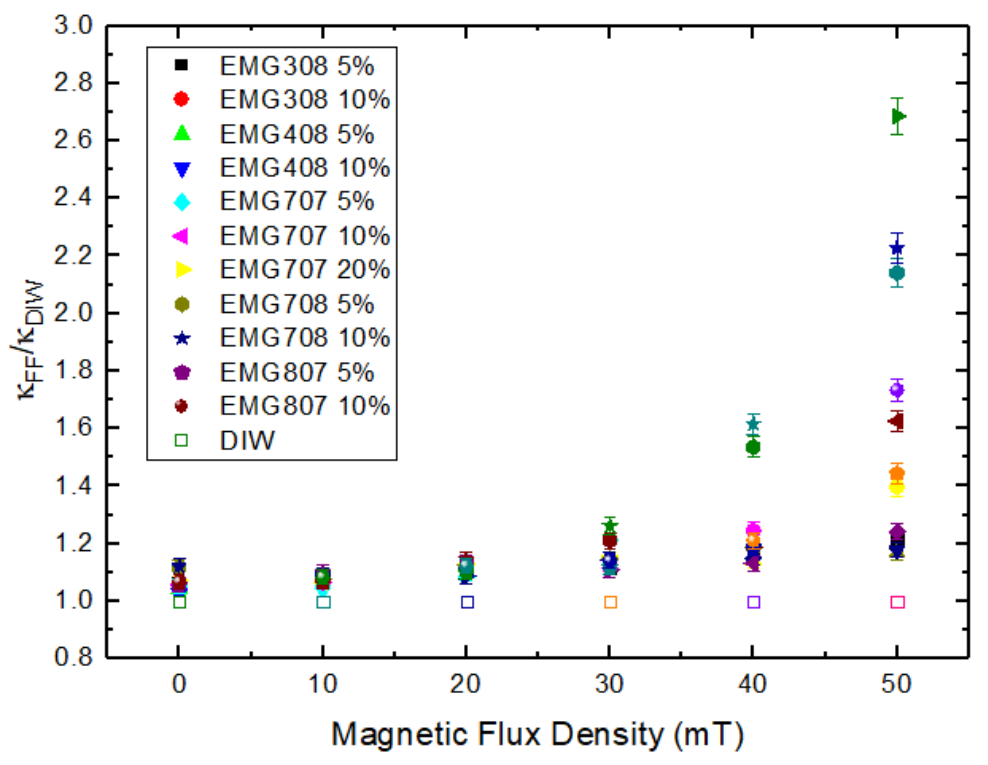

Figure 10: Measured thermal conductivity ratio ( $\left.\mathrm{K}_{\mathrm{FF}} / \mathrm{K}_{\mathrm{DIw}}\right)$ with magnetic field @ $25^{\circ} \mathrm{C}$

\subsection{Single Phase Flow Heat Transfer}

3.2.1 Diluted Ferrofluid Samples (Without a Magnetic Field)

Generally, we found that there is minimal to no enhancement of heat transfer without an external magnetic field (See Figure 11). 


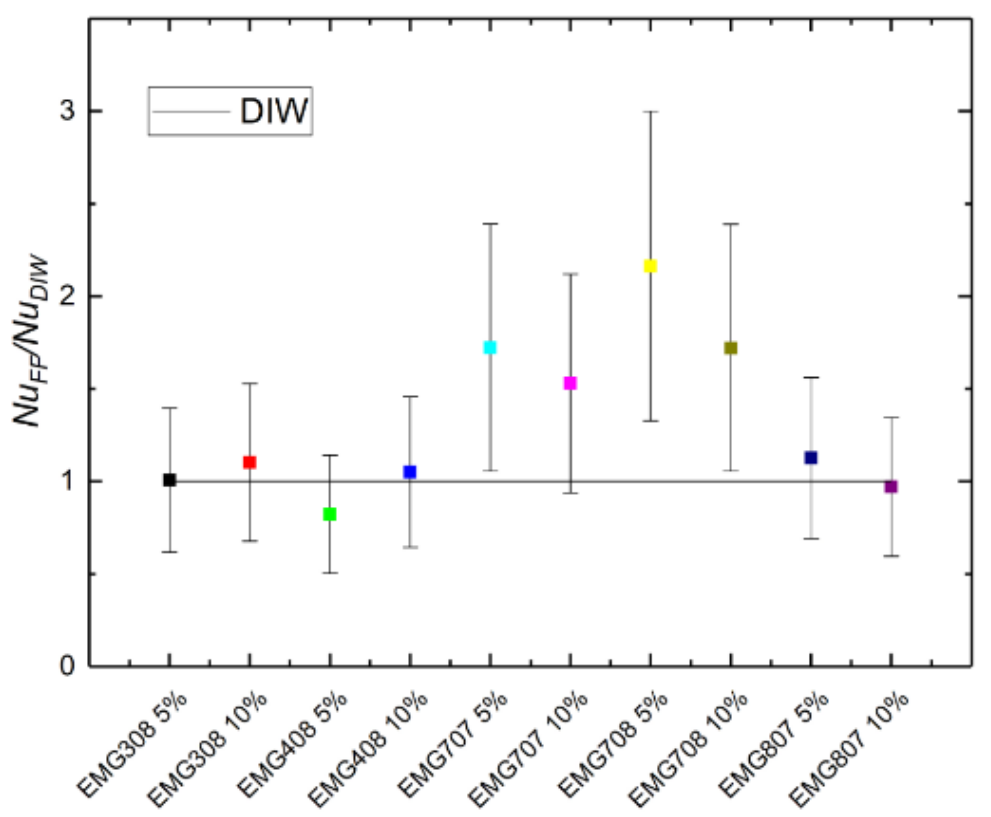

Figure 11: Measured Nu ratio $\left(N u_{F F} / N u_{D I w}\right)$ without magnetic field @ Re=11.6

\subsubsection{Diluted Ferrofluid Samples (With a Magnetic Field)}

Magnetic field strengths of 10, 20,30, 40 and $50 \mathrm{mT}$ were applied to the fluid flow along the heated section. Generally, it was observed that $\mathrm{Nu}$ decreases with increasing magnetic field strength for all diluted ferrofluid samples (See Figure 12). It can also be observed that at a lower magnetic flux of $10 \mathrm{mT}$, for certain ferrofluid samples (EMG707 10\%, EMG708 10\%, EMG807 5\%) heat transfer rate is higher compared to $0 \mathrm{mT}$, and that $\mathrm{Nu}$ decreases significantly when the magnetic flux is $30 \mathrm{mT}$ and above (See Figure 13). This could be attributed to the solid magnetic nanoparticles getting attracted to, and at high enough fluxes, pinned in place against the wall of the channel under the action of the magnetic field. The removal of the nanoparticles from the carrier fluid reduces the effective thermal conductivity of the mixture. This in turn is detrimental to heat transfer at the area where magnetic flux is applied. This particle trapping behaviour is explained by Hejazian and Nguyen [28]. They explain how the solid magnetic nanoparticle escapes, focuses into a line, until they reach a maximum field zone and become almost stationary being trapped at its centre. Hatami et al. [29] also found that heat transfer decreases with the application of an external magnetic field. 


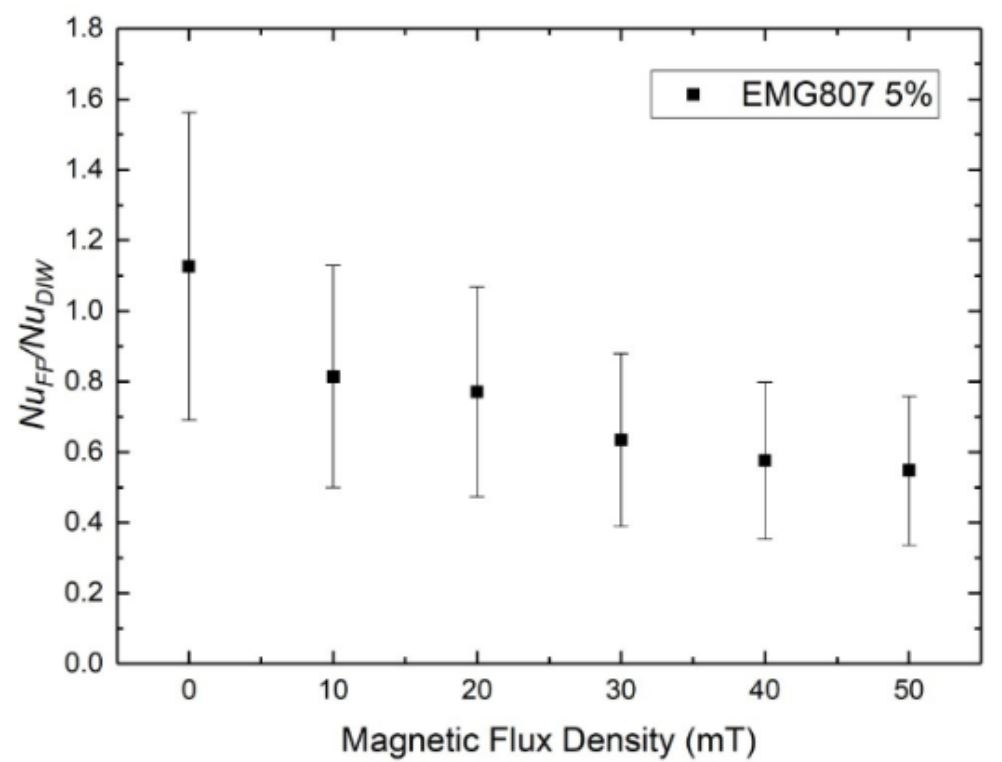

Figure 12: Nu ratio vs magnetic flux density of EMG807 5\% @ Re= 11.6

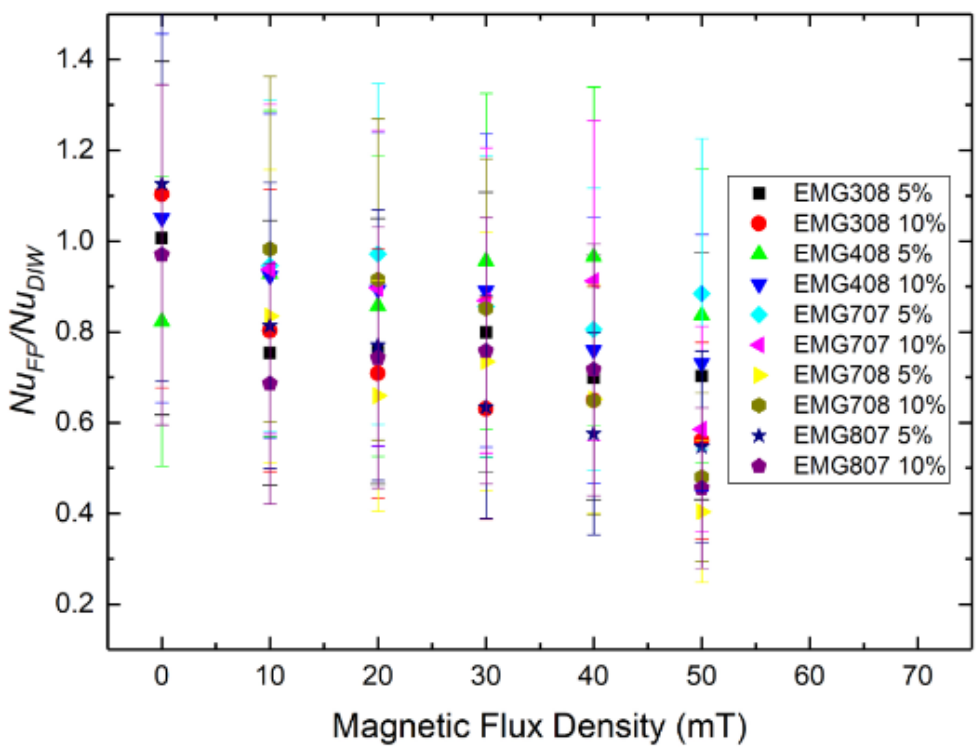

Figure 13: Nu ratio vs magnetic flux density @ Re = 11.6

Figure 14 shows a schematic of how the effective thermal conductivity is decreased due to the magnetic field during the flow. We found that a thermal conductivity ratio of $\mathrm{K}_{\text {eff }} / \mathrm{K}_{\mathrm{DIW}}$ for EMG707 20\% was 1.07 (See Figure 10).

To calculate the effective thermal conductivity in the presence of a magnetic field (Keff $f^{\prime}$, we assume that the solid magnetic nanoparticles get stacked in the region of highest magnetic flux as a complete solid, and take the average thickness of the solid nanoparticle layer $\left(\mathrm{h}_{\mathrm{FF}}\right)$ such that the thickness layer ratio $\left(\mathrm{h}_{\mathrm{FF}} / \mathrm{h}_{\mathrm{DIW}}\right)$ reflects upon the effective thermal conductivity ratio $\left(h_{F F}: h_{D I W}=K_{\text {eff: }} K_{D I W}\right)$. Hence, $K_{\text {eff }}{ }^{\prime}$ is expressed as 


$$
\kappa_{\text {eff }}^{\prime}=\left(\frac{h_{D I W}}{h}\right) \kappa_{D I W}+\left(\frac{h_{F F}}{h}\right) \kappa_{\text {eff }}
$$

where Keff' represents the effective thermal conductivity of the ferrofluid in the presence of a magnetic field in $\mathrm{W} /(\mathrm{m} \cdot \mathrm{K}), \mathrm{h}_{\text {DIW }}$ and $\mathrm{h}_{\mathrm{FF}}$ are the thickness layers of DIW and the solid magnetic nanoparticle $\left(\mathrm{Fe}_{3} \mathrm{O}_{4}\right)$ respectively in $\mathrm{m}, \mathrm{h}$ is the total thickness of the channel in $\mathrm{m}, \mathrm{KDIw}$ and Keff are the thermal conductivities of DIW and $\mathrm{Fe}_{3} \mathrm{O}_{4}$ respectively in $\mathrm{W} /(\mathrm{m} \cdot \mathrm{K})$. Using this approach, we calculated the effective thermal conductivity value of Keff ${ }^{\prime}=0.559 \mathrm{~W} /(\mathrm{m} \cdot \mathrm{K})$ for EMG707 10\% at a flow rate of $2 \mathrm{~mL} / \mathrm{h}$ and a magnetic flux of $200 \mathrm{mT}$. This value is lower than compared to the effective thermal conductivity obtained when the magnetic particles were in suspension without the effect of an external magnetic field (i.e. $\mathrm{Keff}_{\mathrm{K}} / \mathrm{KIW}=1.07 \mathrm{~W} /(\mathrm{m} \cdot \mathrm{K}) \mathrm{vs}$ $\left.K_{\text {eff }}^{\prime} / K_{\text {DIW }}=0.916 \mathrm{~W} /(\mathrm{m} \cdot \mathrm{K})\right)$.

However, it was also observed that the obtained $\mathrm{Nu}$ for zero magnetic flux was lower than the first round of measurements. This can be attributed to the samples themselves becoming unstable due to oxidization from other testing, thus affecting the results. To obtain more accurate results, in future work we will fabrication ferrofluids in-house.

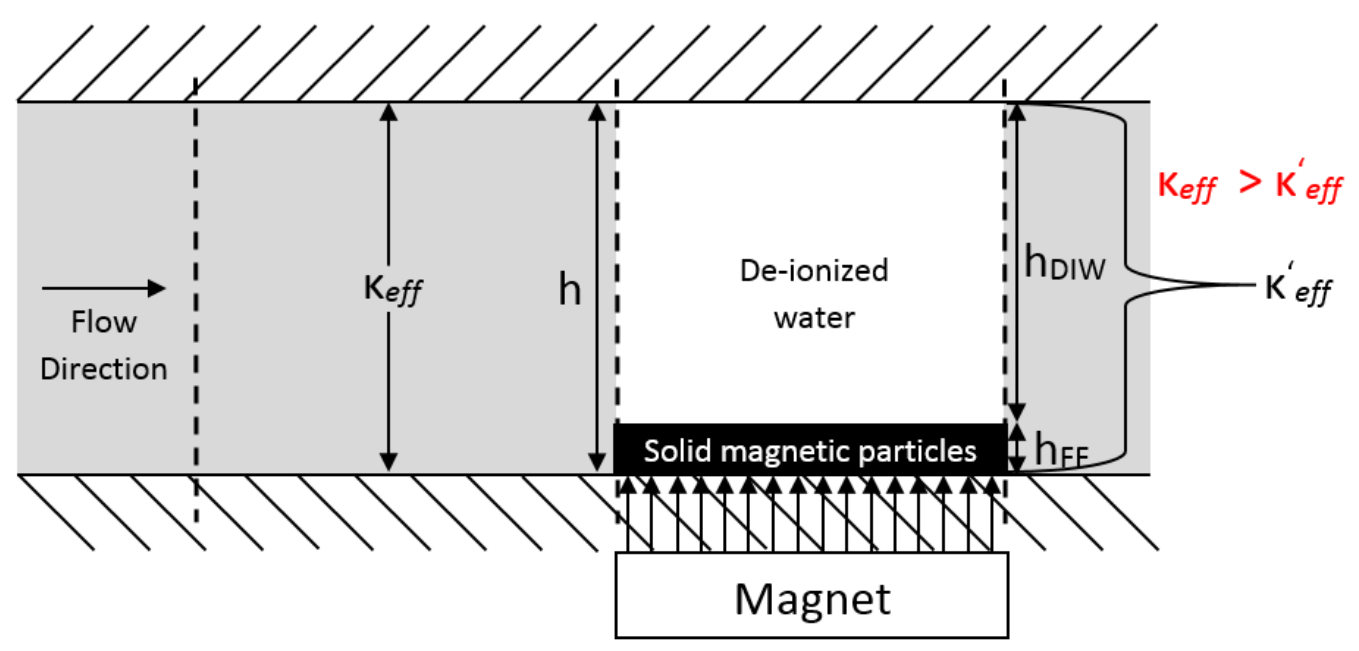

Figure 14: Effective thermal conductivity phenomenon

\subsection{Flow Visualization}

Magnetic particle build-up was visualized to explain the phenomenon of effective thermal conductivity. Magnetic particles build up against the channel wall if the magnetic flux strength is greater than the hydrodynamic force on the particles. At a flow rate of $2 \mathrm{~mL} / \mathrm{h}$ (See Figure 15a), and a magnetic flux of $200 \mathrm{mT}$, we observed that the rate of growth of the deposited layer was $0.283 \mu \mathrm{m} / \mathrm{s}$. However, for a flow rate of $5 \mathrm{~mL} / \mathrm{h}$ (See Figure 15b), no build-up of magnetic particles was observed. This effect can be seen in the sequence of images shown in Figure 15. 


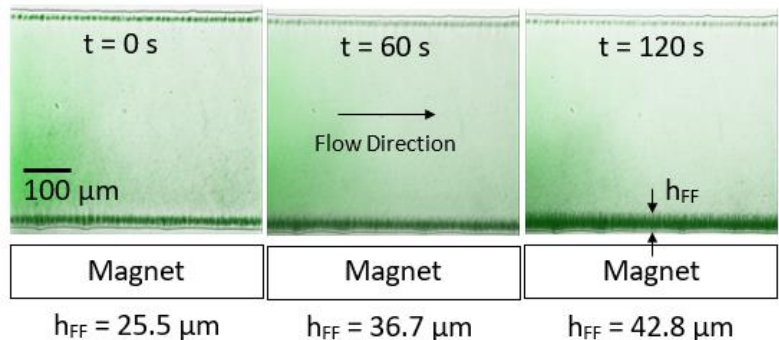

(a)

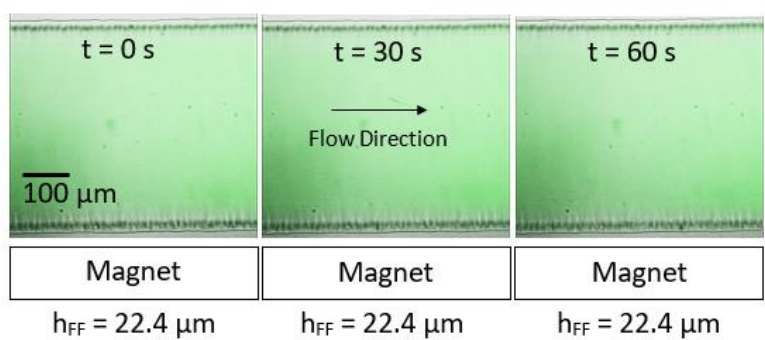

(b)

Figure 15: Magnetic particle build up @ (a) $\dot{Q}=2 \mathrm{~mL} / \mathrm{h}$, (b) $\dot{Q}=5 \mathrm{~mL} / \mathrm{h} \mathrm{B}=200 \mathrm{mT}$

To understand the trajectory of the magnetic nanoparticles as they come out from a polydisperse solution due to an external magnetic field. We modelled the balance of hydrodynamic and magnetic forces as follows. We assume that there are only two forces acting on the particle. The first is the external magnetic force, $F_{B}$ expressed as

$$
F_{B}=\mu_{0} H^{2} d^{2}=\frac{B^{2}}{\mu_{0}} d^{2}
$$

where $\mu_{0}$ is the permeability of vacuum in free space in $\mathrm{m} \cdot \mathrm{kg} / \mathrm{s}^{2} \mathrm{~A}^{2}, \mathrm{H}$ is the magnetic field strength in $A / \mathrm{m}, B$ is the magnetic flux density in $T, \rho$ is density of the particle in $\mathrm{kg} / \mathrm{m}^{3}$, and $d$ is the diameter of the particle in $\mathrm{m}$.

The other force present is drag force, $F_{D}$ acting against the motion of the particle, which can be expressed as

$$
F_{D}=-3 \pi \mu v_{y} d
$$

where $\mu$ is the viscosity of the ferrofluid in $\mathrm{kg} /(\mathrm{s} \cdot \mathrm{m})$, and $\mathrm{v}_{\mathrm{y}}$ is the velocity of the particle in the $\mathrm{y}$ component in $\mathrm{m} / \mathrm{s}$.

The critical value of $v_{y}$ is when $F_{B}=F_{D}$ which can be expressed as

$$
v_{y, \text { critical }}=\frac{B^{2} d}{\mu_{0}(-3 \pi \mu)}
$$

Taking upwards as positive (See Figure 15), the sum of forces acting in the y-direction is;

$$
-F_{B}+F_{D}=m \frac{d v_{y}}{d t}
$$

where $\mathrm{m}$ is the mass of the particle in $\mathrm{kg}, \mathrm{dv} / \mathrm{dt}$ is the rate of change of velocity of the particle in the $y$-direction in $\mathrm{m} / \mathrm{s}$. 
Assuming that magnetic field is constant throughout the thickness of the channel, equation

(9) can be integrated as such

$$
\int \frac{m}{-3 \pi \mu v_{y} d-F_{B}} d v_{y}=\int d t .
$$

Hence,

$$
t=-\frac{m}{3 \pi \mu d} \ln \left|-3 \pi \mu v_{y} d-F_{B}\right|+C
$$

We assume $v_{y}=0 \mathrm{~m} / \mathrm{s}$ at $\mathrm{t}=0 \mathrm{~s}$, therefore,

$$
C=\frac{m}{3 \pi \mu d} \ln \left|-F_{B}\right|
$$

Therefore, we can express $v_{y}$ as

$$
v_{y}=\frac{F_{B}\left(1+e^{\frac{-3 \pi \mu d t}{m}}\right)}{-3 \pi \mu d}
$$

where $v_{y}$ is the velocity of the particle in the $y$-component.

To find the $y$-position of the particle, we integrate $v_{y}$ as such

$$
y=y_{0}+\frac{F_{B}}{-3 \pi \mu d} \int\left(1+e^{\frac{-3 \pi \mu d t}{m}}\right) d t=y_{0}+\frac{F_{B}}{-3 \pi \mu d}\left(t+\frac{m e^{\frac{-3 \pi \mu d t}{m}}}{-3 \pi \mu d}\right)
$$

where $y$ is the $y$-position of the particle in $m, y_{0}$ is the initial $y$-position of the particle in $m, F_{B}$ is the magnetic force acting on a particle in $N, \mu$ is the viscosity of the fluid in Pa.s, $d$ is the diameter of the particle in $\mathrm{m}, \mathrm{m}$ is mass of the particle in $\mathrm{kg}$, and $\mathrm{t}$ is time in $\mathrm{s}$.

For laminar flow in a rectangular channel, the velocity profile $v_{x}$ is expressed as

$$
v_{x}=v(y, z)=\frac{16 a^{3}}{\mu \pi^{3}}\left(-\frac{d P}{d x}\right) \sum_{i=1,3,5, \ldots}^{\infty}(-1)^{\frac{i-1}{2}}\left(1-\frac{\cosh \left(\frac{i \pi z}{2 a}\right)}{\cosh \left(\frac{i \pi b}{2 a}\right)}\right) \times \frac{\cos \left(\frac{i \pi y}{2 a}\right)}{i^{3}}=\frac{d x}{d t}
$$

where $v(y, z)=v_{x}=d x / d t$ which is the $x$-component of velocity in $m / s,-a \leq y \leq a$ is the width of the channel in $m,(-d P / d x)$ is the pressure gradient in $\mathrm{Pa} / \mathrm{m}$, and $-\mathrm{b} \leq \mathrm{z} \leq \mathrm{b}$ is the height of the channel in $\mathrm{m}[30]$.

To enable simple integration, we approximate the solution of $v_{x}$ in the channel miplane by a fourth order polynomial. For a flow rate of $\dot{Q}=0.5 \mathrm{~mL} / \mathrm{h}$, we obtain the equation as 


$$
v_{x}=-6 E+11 y^{4}+223394 y^{3}-7232.7 y^{2}-0.0104 y+0.0026
$$

Substituting equation (7) into equation (9), and neglecting the exponential term as it is very small, we obtain the following expression

$$
\begin{aligned}
& v_{x}=\frac{d x}{d t}=-6 E+11\left(y_{0}+\frac{F_{B}}{-3 \pi \mu d} t\right)^{4}+223394\left(y_{0}+\frac{F_{B}}{-3 \pi \mu d} t\right)^{3} \\
& -7232.7\left(y_{0}+\frac{F_{B}}{-3 \pi \mu d} t\right)^{2}-0.0104\left(y_{0}+\frac{F_{B}}{-3 \pi \mu d} t\right)+0.0026
\end{aligned}
$$

Integrating, we obtain the following expression for $\mathrm{x}$-position with respect to time

$$
\begin{aligned}
& x=x_{0}+\frac{-6 E+11\left(y_{0}+\frac{F_{B}}{-3 \pi \mu d} t\right)^{5}(-3 \pi \mu d)}{5 F_{B}}+\frac{223394\left(y_{0}+\frac{F_{B}}{-3 \pi \mu d} t\right)^{4}(-3 \pi \mu d)}{4 F_{B}} \\
& -\frac{7232.7\left(y_{0}+\frac{F_{B}}{-3 \pi \mu d} t\right)^{3}(-3 \pi \mu d)}{3 F_{B}}-\frac{0.0104\left(y_{0}+\frac{F_{B}}{-3 \pi \mu d} t\right)^{2}(-3 \pi \mu d)}{2 F_{B}}+0.0026 t .
\end{aligned}
$$

where $x$ is the $x$-position of the particle in $m, x_{0}$ is the initial $x$-position of the particle in $m, F_{B}$ is the magnetic force acting on a particle in $N, \mu$ is the viscosity of the fluid in Pa.s, $d$ is the diameter of the particle in $\mathrm{m}$, and $\mathrm{t}$ is time in $\mathrm{s}$.

Figure 16 below shows the trajectory of magnetic particles with different initial positions within the channel, $y_{0}$, at a relative $x$-position of $x_{0}=0$. Also shown is the centreline velocity profile of the flow for a flow rate of $0.5 \mathrm{~mL} / \mathrm{h}$. Along each path line, the time step between data points is $\Delta t=1 \mathrm{~s}$. The results here indicate the attraction of the particles towards the wall as they advect with the flow under the influence of the magnetic force. Flow visualization further supports this effect. Figure 17 shows representative particle trajectories at the same flow conditions via digitally overlaying 100 frames of a sequence of images. To prevent oversaturation, the images' greyscale was inverted, hence, moving magnetic particles appear white in the image. A number of slow moving particles can be seen to be drawn towards the bottom wall of the channel, creating piecewise streak lines on a diagonal to the direction of flow. Larger particles moving at higher velocities in the centre of the channel do not experience the same gradient and so appear as a number of individual white blotches separated by much larger distanced. As an artefact of the processing steps used, the stationary magnetic particles remain dark as shown at the bottom of the image. 


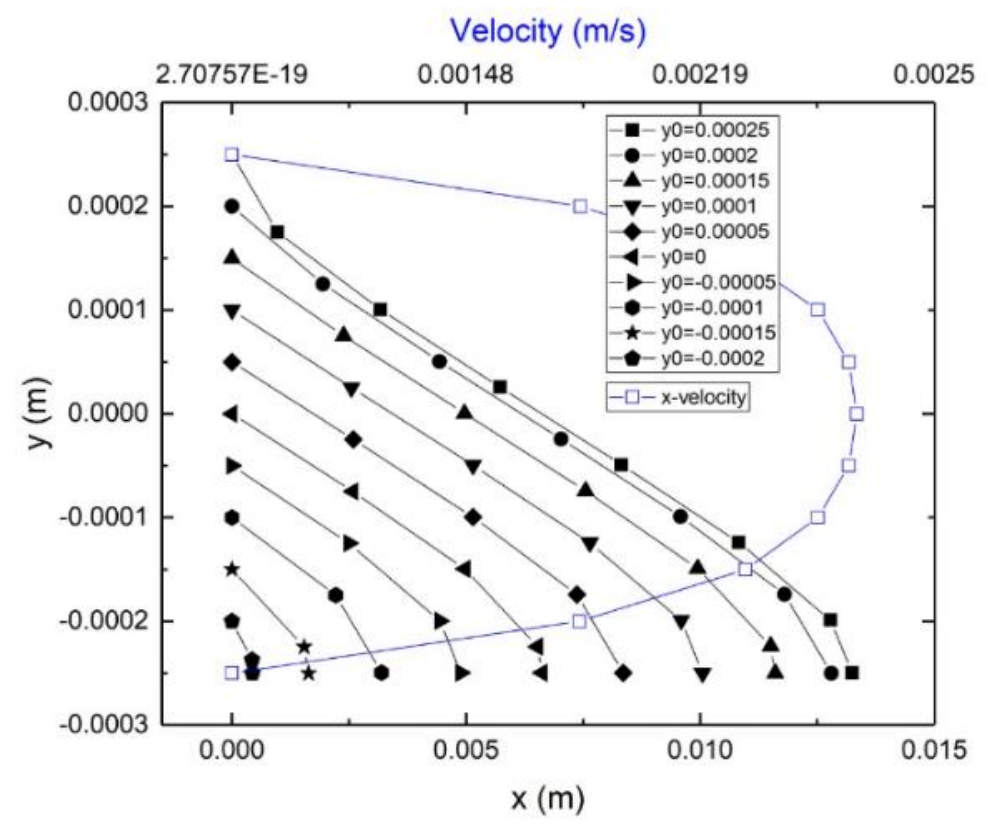

Figure 16: Magnetic particle trajectory and velocity profile for rectangular channel @ 0.5 $\mathrm{mL} / \mathrm{h}(\operatorname{Re}=0.36)$

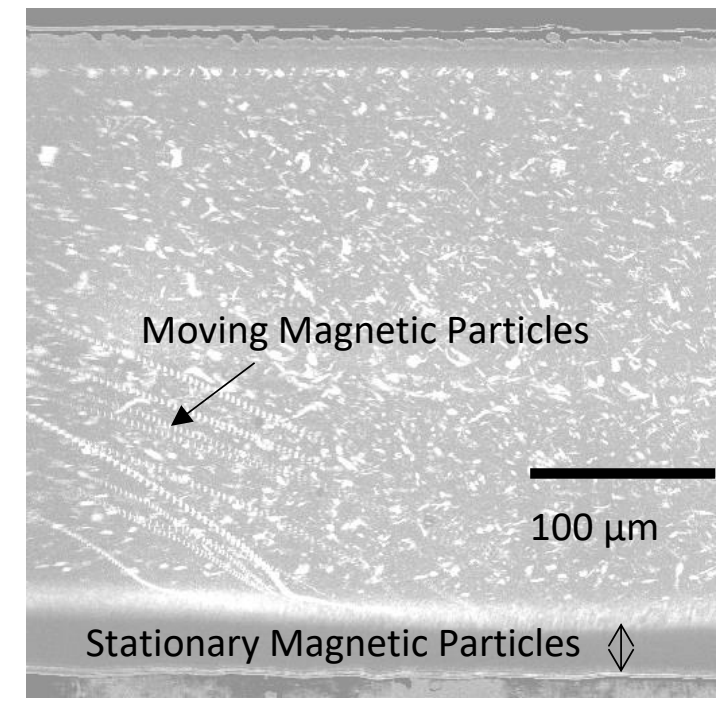

Figure 17: Flow visualization stitch of magnetic particle trajectory for $\Delta \mathrm{t}=8 \mathrm{~s} @ 0.5 \mathrm{~mL} / \mathrm{h}$

$$
(\operatorname{Re}=0.36)
$$

\section{$4 \quad$ Conclusions and Recommendations}

We have investigated the effect of various commercial water-based ferrofluid types with a dilution factor of $5 \%$ and $10 \%$, on the heat transfer properties under the application of an external magnetic field. We have shown the importance of characterizing the ferrofluid material to better understand the heat transfer enhancement effect. We found that generally, a higher solid volume concentration of magnetic nanoparticles enhances heat 
transfer rates. We recorded about a $100 \%$ enhancement in thermal conductivity for EMG708 $10 \%$ under a magnetic flux of $50 \mathrm{mT}$ at RTP compared to DIW, and about a $116 \%$ enhancement in heat transfer for EMG708 5\% without a magnetic field. However, we observed that heat transfer rate was diminished with increasing magnetic field strength which may be attributed to the solid magnetic nanoparticles becoming trapped against the channel wall in the magnetized area. We also showed experimentally and numerically that the effective thermal conductivity of the ferrofluid is reduced due to the trapping of the magnetic particles. The balance of forces between magnetic and hydrodynamic is what determines magnetic particle trapping, which also allowed us to predict particle trajectory.

It was also observed that viscosity increases with an increase in magnetic flux, but only to a small extent. The largest increment of viscosity was for EMG308 10\%, with an increment of $5 \%$ at a magnetic flux of $50 \mathrm{mT}$, compared to the viscosity at $0 \mathrm{mT}$. It was difficult to associate the enhanced heat transfer phenomenon to a material characteristic of the ferrofluid due to the commercial nature of the substance. Therefore, we will be self-fabricating ferrofluids for future experiments. Future works also include two-phase liquid-liquid ferrofluidic plug flow, and pressure drop experiments. Mixing can also be enhanced by using a non-uniform magnetic field which will also be investigated for future studies.

\section{Acknowledgements}

We thank David Dunstan and RMIT's MNRF, RMMF and AMP for assistance, Mark Greaves from the CSIRO Manufacturing Electron Microscopy, Digital Imaging and Surface Analysis Facility within the Characterisation Group for his contribution to the optical profiling experiment, and the Australian Research Council for funding this research (linkage project ID LP150100153).

\section{References}

[1] T. E. Sarvey, Y. Zhang, L. Zheng, P. Thadesar, R. Gutala, C. Cheung, et al., "Embedded Cooling Technologies for Densely Integrated Electronic Systems," in Custom Integrated Circuits Conference, San Jose, CA, USA, 2015, pp. 1-8.

[2] D. B. Tuckerman and R. F. W. Pease, "High-Performance Heat Sinking for VLSI," IEEE Electron Device Letters, vol. 2, pp. 126-129, 1981.

[3] R. Taylor, S. Coulombe, T. Otanicar, P. Phelan, A. Gunawan, W. Lv, et al., "Small particles, big impacts: A review of the diverse applications of nanofluids," Journal of Applied Physics, vol. 113, p. 011301, 2013.

[4] R. E. Rosensweig, Ferrohydrodynamics, Dover edition ed. Mineola, New York: Dover Publications, Inc., 1997.

[5] N. A. Clark, "Ferromagnetic ferrofluids," Soft-Matter Physics, vol. 504, pp. 229-230, 2013.

[6] M. Abareshi, E. K. Goharshadi, S. M. Zebarjad, H. K. Fadafan, and A. Youssefi, "Fabrication, characterization and measurement of thermal conductivity of Fe304 nanofluids," Journal of Magnetism and Magnetic Materials, vol. 322, pp. 3895-3901, 2010.

[7] M. Alsaady, R. Fu, B. Li, R. Boukhanouf, and Y. Yan, "Thermo-physical properties and thermo-magnetic convection of ferrofluid," Applied Thermal Engineering, vol. 88, pp. 14-21, 2015. 
[8] E. Ghasemi, A. Mirhabibi, and M. Edrissi, "Synthesis and rheological properties of an iron oxide ferrofluid," Journal of Magnetism and Magnetic Materials, vol. 320, pp. 2635-2639, 2008.

[9] W. Jiang and L. Wang, "Monodisperse magnetite nanofluids: Synthesis, aggregation, and thermal conductivity," Journal of Applied Physics, vol. 108, 2010.

[10] Z. Che, N. T. Nguyen, and T. N. Wong, "Analysis of chaotic mixing in plugs moving in meandering microchannels," Phys Rev E Stat Nonlin Soft Matter Phys, vol. 84, p. 066309, Dec 2011.

[11] N. T. Nguyen and Z. Wu, "Micromixers - a review," Journal of Micromechanics and Microengineering, vol. 15, pp. R1-R16, 2005.

[12] J. Philip, P. D. Shima, and B. Raj, "Enhancement of thermal conductivity in magnetite based nanofluid due to chainlike structures," Applied Physics Letters, vol. 91, 2007.

[13] J. Philip, P. D. Shima, and B. Raj, "Evidence for enhanced thermal conduction through percolating structures in nanofluids," IOP Science Nanotechnology, vol. 19, 2008.

[14] A. Gavili, F. Zabihi, T. D. Isfahani, and J. Sabbaghzadeh, "The thermal conductivity of water base ferrofluid under magnetic field," Experimental Thermal and Fluid Science, vol. 41, pp. 94-98, 2012.

[15] C. L. Altan, A. Elkatmis, M. Yüksel, N. Aslan, and S. Bucak, "Enhancement of thermal conductivity upon application of magnetic field to Fe3O4 nanofluids," Journal of Applied Physics, vol. 110, 2011.

[16] C. L. Altan, b. Gurten, N. A. J. M. Sommerdijk, and S. Bucak, "Deterioration in effective thermal conductivity of aqueoues magnetic nanofluids," Journal of Applied Physics, vol. 116, 2014.

[17] M. J. Pastoriza-Gallego, L. Lugo, J. L. Legido, and M. M. Piñeiro, "Enhancement of thermal conductivity and volumetric behaviour of Fe $\mathrm{x} \mathrm{O}$ y nanofluids," Journal of Applied Physics, vol. 110, 2011.

[18] Q. Li, Y. Xuan, and J. Wang, "Experimental investigations on transport properties of magnetic fluids," Experimental Thermal and Fluid Science, vol. 30, pp. 109-116, 2005.

[19] L. Wang, Y. Wang, X. Yan, X. Wang, and B. Feng, "Investigation on viscosity of Fe3O4 nanofluid under magnetic field," International Communications in Heat and Mass Transfer, vol. 72, pp. 23-28, 2016.

[20] M. Devi and D. Mohanta, "Rheological Properties of Iron Oxide Based Ferrofluids," Allahabad (India), 2009.

[21] M. Pinho, B. Brouard, J. M. Ge'nevaux, N. Dauchez, O. Volkova, H. Mézière, et al., "Investigation into ferrofluid magnetoviscous effects under an oscillating shear flow," Journal of Magnetism and Magnetic Materials, vol. 323, pp. 2386-2390, 2011.

[22] V. Saggiomo and A. H. Velders, "Simple 3D Printed Scaffold-Removal Method for the Fabrication of Intricate Microfluidic Devices," Materials Views, Advanced Science, vol. 2, pp. 1-5, 2015.

[23] H. W. Coleman and W. G. Steele, Experimentation, Validation, and Uncertainty Analysis for Engineers. Hoboken, NJ, USA: John Wiley \& Sons, Inc., 2009.

[24] C. Stanley, "Experimental Investigation in a Cylindrical Orifice," Doctor of Philosophy, School of Mechanical and Manufacturing Engineering, The University of New South Wales, 2012.

[25] A.-H. Lu, E. L. Salabas, and F. Schüth, "Magnetic Nanoparticles: Synthesis, Protection, Functionalization, and Application," Angewandte Chemie International Edition, vol. 46, pp. 1222-1244, 2007. 
[26] H. Zhu, C. Zhang, S. Liu, Y. Tang, and Y. Yin, "Effects of nanoparticle clustering and alignment on thermal conductivities of Fe3O4 aqueous nanofluids," Applied Physics Letters, vol. 89, 2006.

[27] Q. Li and Y. Xuan, "Experimental investigation on heat transfer characteristics of magnetic fluid flow around a fine wire under the influence of an external magnetic field," Experimental Thermal and Fluid Science, vol. 33, pp. 591-596, 2009.

[28] M. Hejazian and N. T. Nguyen, "Magnetofluidic concentration and separation of nonmagnetic particles using two magnet arrays," Biomicrofluidics, vol. 10, 2016.

[29] N. Hatami, A. K. Banari, A. Malekzadeh, and A. R. Pouranfard, "The effect of magnetic field on nanofluids heat transfer through a uniformly heated horizontal tube," Physics Letters A, vol. 381, pp. 510-515, 2017.

[30] F. M. White, Viscous Fluid Flow, Second Edition ed. United States of America: McGrawHill Inc., 1991.

[31] V. E. Fertman, L. E. Golovicher, and N. P. Matusevich, "Thermal Conductivity of Magnetite Magnetic Fluids," Journal of Magnetism and Magnetic Materials, vol. 65, pp. 211-214, 1987.

[32] A. Karimi, M. Goharkhah, M. Ashjaee, and M. B. Shafii, "Thermal Conductivity of Fe2O3 and Fe3O4 Magnetic Nanofluids Under the Influence of Magnetic Field," International Journal of Thermophysics, vol. 36, pp. 2720-2739, 2015.

[33] W. Yu, H. Xie, L. Chen, and Y. Li, "Enhancement of thermal conductivity of kerosenebased Fe3O4 nanofluids prepared via phase transfer method," Colloids and Surfaces A: Physiochemical and Engineering Aspects, vol. 355, pp. 109-113, 2009.

[34] K. Parekh and H. S. Lee, "Magnetic field induced enhancement in thermal conductivity of magnetite nanofluid," Journal of Applied Physics, vol. 107, 2010.

[35] A. Vatani, N.-T. Nguyen, P. L. Woodfield, and D. V. Dao, "Effect of temperature on the thermal conductivity of ferrofluid in a non-uniform magnetic field," presented at the The 10th Australasian Heat and Mass Transfer Conference, Brisbane, Australia, 2016.

[36] R. Y. Hong, Z. Q. Ren, Y. P. Han, H. Z. Li, Y. Zheng, and J. Ding, "Rheological properties of water-based Fe304 ferrofluids," Chemical Engineering Journal, vol. 62, pp. 59125924, 2007. 


\section{Appendix A}

Table A1: Past Experimental results for Thermal Conductivity of Ferrofluids

\begin{tabular}{|c|c|c|c|c|c|c|c|c|}
\hline 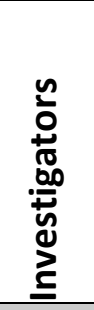 & 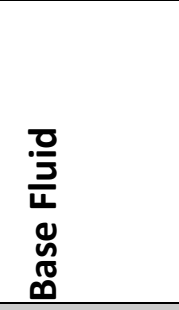 & 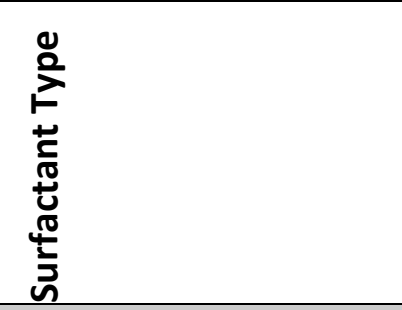 & 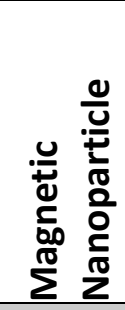 & 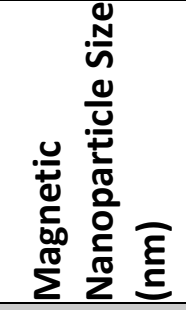 & 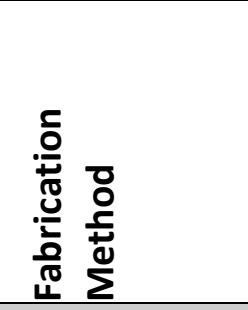 & 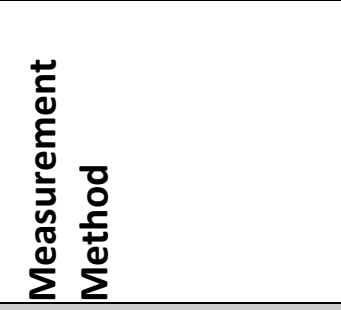 & 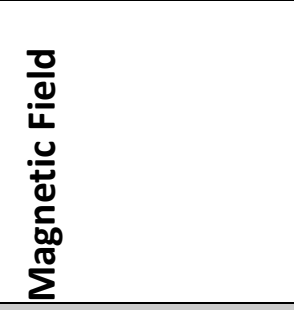 & 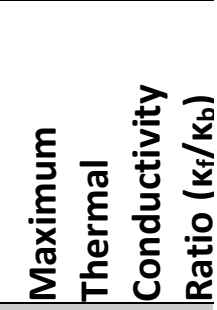 \\
\hline [18] & Water & $\begin{array}{l}\text { Sodium } \\
\text { Dodecylbenesulfonate } \\
\text { (activator) }\end{array}$ & $\mathrm{Fe}$ & 26 & Direct Mixing & $\begin{array}{l}\text { Transient hot-wire } \\
\text { - two wire style } \\
\text { method }\end{array}$ & $\begin{array}{l}\text { // magnetic } \\
\text { field - induced } \\
\text { by solenoid ( } 90 \\
\mathrm{mT} \text { ) } \\
\mathrm{L} \text { magnetic } \\
\text { field - } \\
\text { permanent } \\
\text { magnet ( } 25 \mathrm{mT} \text { ) }\end{array}$ & $\begin{array}{l}\mathrm{B}(/ /), \phi= \\
5 \% ; 1.16 \\
\mathrm{~B}(\llcorner),(\phi= \\
5 \%) ; 1.45\end{array}$ \\
\hline [12] & Kerosene & Oleic Acid $(t=1.5 \mathrm{~nm})$ & $\mathrm{Fe}_{3} \mathrm{O}_{4}$ & 6.7 & Unknown & $\begin{array}{l}\text { KD2 Pro (transient } \\
\text { hot-wire) } \\
\text { Vial ( } \mathrm{d}=24 \mathrm{~mm} \text {; } \\
\text { might be too small } \\
\text { for accurate } \\
\text { measurements) }\end{array}$ & $\begin{array}{l}\text { Solenoid-like } \\
\text { electromagnet } \\
(50 \mathrm{mT})\end{array}$ & $\begin{array}{l}\phi= \\
1.71 \% \\
2.15 \\
B=12 \mathrm{mT} \\
\phi=6.3 \% \\
3.25\end{array}$ \\
\hline
\end{tabular}




\begin{tabular}{|c|c|c|c|c|c|c|c|c|}
\hline [13] & Kerosene & Oleic Acid $(t=1.5 \mathrm{~nm})$ & $\mathrm{Fe}_{3} \mathrm{O}_{4}$ & 6.7 & Unknown & $\begin{array}{l}\text { KD2 Pro (transient } \\
\text { hot-wire) } \\
\text { Vial (d = } 24 \mathrm{~mm} \text {; } \\
\text { might be too small } \\
\text { for accurate } \\
\text { measurements) }\end{array}$ & $\begin{array}{l}\text { Solenoid-like } \\
\text { electromagnet } \\
(50 \mathrm{mT})\end{array}$ & $\begin{array}{l}\phi= \\
1.71 \% ; \\
2.25 \\
B(/ /)=40 \\
\mathrm{mT}, \phi= \\
6.3 \% ; 4.0\end{array}$ \\
\hline [14] & Water & Tri-sodium-citrate & $\mathrm{Fe}_{3} \mathrm{O}_{4}$ & $10+/-3$ & Co-precipitation & $\begin{array}{l}\text { KD2 Pro (transient } \\
\text { hot-wire) } \\
\text { Test area ( } d=10 \\
\mathrm{~mm} \text {; might be too } \\
\text { small for accurate } \\
\text { measurements) }\end{array}$ & Helmholtz coils & $\begin{array}{l}B(\llcorner)=60 \\
\mathrm{mT}, \phi= \\
5 \% ; 1.67 \\
B(\llcorner)=100 \\
\mathrm{mT}, \phi= \\
5 \% ; 3.0\end{array}$ \\
\hline [31] & Hydrocarbon & Oleic Acid & $\mathrm{Fe}_{3} \mathrm{O}_{4}$ & Unknown & Unknown & Transient hot-wire & None & $\begin{array}{l}\phi=2 \% ; \\
2.8\end{array}$ \\
\hline [32] & Water & $\begin{array}{l}\text { Tetramethyl ammonium } \\
\text { hydroxide (TMAH) }\end{array}$ & $\mathrm{Fe}_{2} \mathrm{O}_{3}$ & 9 & Co-precipitation & $\begin{array}{l}\text { KD2 Pro (transient } \\
\text { hot-wire) }\end{array}$ & $\begin{array}{l}\llcorner\text { magnetic } \\
\text { field - Iron Core } \\
\text { Electromagnet }\end{array}$ & $\begin{array}{l}\phi=4.8 \% \\
1.25\end{array}$ \\
\hline [6] & Water & TMAH & $\mathrm{Fe}_{3} \mathrm{O}_{4}$ & 8.4-10.9 & Co-precipitation & $\begin{array}{l}\text { KD2 Pro (transient } \\
\text { hot-wire) }\end{array}$ & None & $\begin{array}{l}\phi=4.8 \% \\
1.22\end{array}$ \\
\hline [33] & Kerosene & Oleic Acid & $\mathrm{Fe}_{3} \mathrm{O}_{4}$ & $\begin{array}{l}15 \\
155(D L S)\end{array}$ & $\begin{array}{l}\text { One-Step Phase } \\
\text { Transfer }\end{array}$ & Short hot-wire & None & $\begin{array}{l}\phi=3 \% \\
1.11\end{array}$ \\
\hline [26] & Water & Ammonium Citrate & $\mathrm{Fe}_{3} \mathrm{O}_{4}$ & $9.8-10$ & Co-precipitation & Transient hot-wire & None & $\begin{array}{l}\phi=1 \% \\
1.34\end{array}$ \\
\hline \multirow[t]{2}{*}{ [16] } & Water & $\begin{array}{l}\text { Oleic Acid (activator); } \\
\text { Citric Acid (surfactant) }\end{array}$ & $\mathrm{Fe}_{3} \mathrm{O}_{4}$ & 6 & $\begin{array}{l}\text { Thermal } \\
\text { Decomposition }\end{array}$ & \multirow{2}{*}{$\begin{array}{l}\text { Flucon } \mathrm{GmBH} \\
\text { Lambda (transient } \\
\text { hot-wire) }\end{array}$} & \multirow[t]{2}{*}{ None } & $\begin{array}{l}\phi=5 \% \\
1.4\end{array}$ \\
\hline & Water & Citric Acid or Capric Acid & & 10 & Co-precipitation & & & $\begin{array}{l}\phi=1.2 \% \\
0.89\end{array}$ \\
\hline
\end{tabular}




\begin{tabular}{|c|c|c|c|c|c|c|c|c|}
\hline [15] & Water & Capric Acid & $\mathrm{Fe}_{3} \mathrm{O}_{4}$ & 10 & Co-precipitation & $\begin{array}{l}\text { Flucon } \mathrm{GmBH} \\
\text { Lambda (transient } \\
\text { hot-wire) }\end{array}$ & $\begin{array}{l}\text { Solenoid-like } \\
\text { electromagnet }\end{array}$ & $\begin{array}{l}\phi=7 \% ; \\
1.048 \\
B(\llcorner)= \\
200 \mathrm{mT}, \phi \\
=1.28 \% ; \\
1.028\end{array}$ \\
\hline \multirow[t]{2}{*}{ [17] } & $\begin{array}{l}\text { Ethylene } \\
\text { Glycol }\end{array}$ & Unknown & $\mathrm{Fe}_{3} \mathrm{O}_{4}$ & $15+/-4$ & Co-precipitation & \multirow[t]{2}{*}{$\begin{array}{l}\text { KD2 Pro (transient } \\
\text { hot-wire) }\end{array}$} & \multirow[t]{2}{*}{ None } & $\begin{array}{l}\phi=6.6 \% \\
1.16\end{array}$ \\
\hline & $\begin{array}{l}\text { Ethylene } \\
\text { Glycol }\end{array}$ & Unknown & $\mathrm{Fe}_{2} \mathrm{O}_{3}$ & $29+/-18$ & $\begin{array}{l}\text { One-Step Phase } \\
\text { Transfer }\end{array}$ & & & $\begin{array}{l}\phi=6.6 \% \\
1.12\end{array}$ \\
\hline [34] & Kerosene & Oleic Acid & $\mathrm{Fe}_{3} \mathrm{O}_{4}$ & 9.9 & Co-precipitation & $\begin{array}{l}\text { Flucon } \mathrm{GmBH} \\
\text { Lambda (transient } \\
\text { hot-wire) }\end{array}$ & $\begin{array}{l}\text { Solenoid-like } \\
\text { electromagnet } \\
(100 \mathrm{mT})\end{array}$ & $\begin{array}{l}\mathrm{B}(\llcorner), \phi= \\
4.7 \% ; 1.23\end{array}$ \\
\hline \multirow[t]{2}{*}{ [9] } & Toluene & Oleic Acid & \multirow[t]{2}{*}{$\mathrm{Fe}_{3} \mathrm{O}_{4}$} & $4-12$ & $\begin{array}{l}\text { Thermal } \\
\text { Decomposition }\end{array}$ & \multirow[t]{2}{*}{$\begin{array}{l}\text { KD2 Pro (transient } \\
\text { hot-wire) }\end{array}$} & \multirow[t]{2}{*}{ None } & Unknown \\
\hline & Water & Poly (acrylic acid) (PAA) & & $4-12$ & $\begin{array}{l}\text { Thermal } \\
\text { Decomposition } \\
\text { + Phase } \\
\text { Transfer }\end{array}$ & & & Unknown \\
\hline [35] & Water & Unknown & $\mathrm{Fe}_{3} \mathrm{O}_{4}$ & $\sim 10$ & Unknown & Transient hot-wire & $\begin{array}{l}\text { Current- } \\
\text { carrying wire (I } \\
=0.5 \mathrm{~A})\end{array}$ & $\begin{array}{l}B(\llcorner), \phi= \\
2 \% ; 1.09\end{array}$ \\
\hline
\end{tabular}


Table A2: Past Experimental results for Viscosity of Ferrofluids

\begin{tabular}{|c|c|c|c|c|c|c|c|c|}
\hline 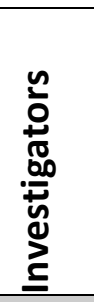 & 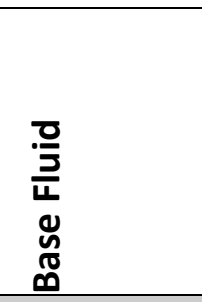 & 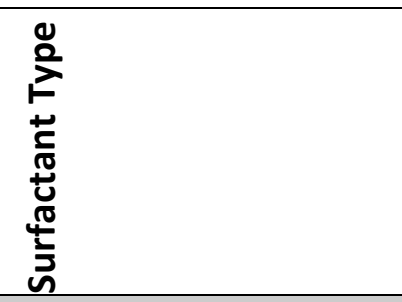 & 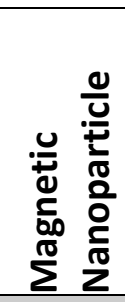 & 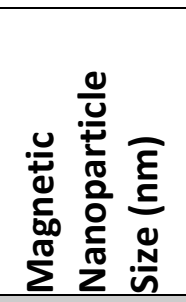 & 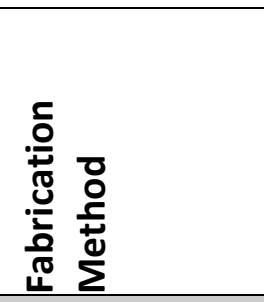 & 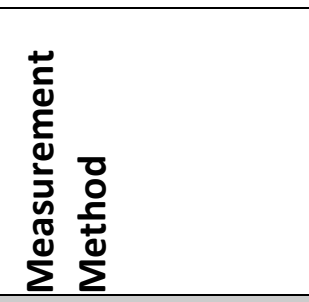 & 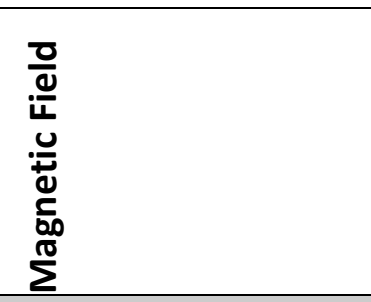 & 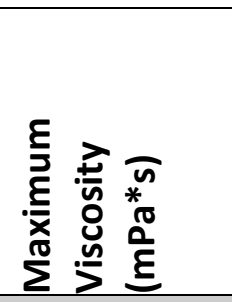 \\
\hline \multirow[t]{2}{*}{ [18] } & Water & Oleic Acid & $\mathrm{Fe}_{3} \mathrm{O}_{4}$ & 20 & $\begin{array}{l}\text { Co- } \\
\text { precipitation }\end{array}$ & \multirow[t]{2}{*}{$\begin{array}{l}\text { Capillary Tube } \\
\text { Viscometer }\end{array}$} & $\begin{array}{l}\text { L magnetic field - } \\
\text { permanent magnet } \\
(25 \mathrm{mT})\end{array}$ & $\begin{array}{l}\phi=2.83 \% \\
25\end{array}$ \\
\hline & Water & $\begin{array}{l}\text { Sodium } \\
\text { Dodecylbenesulfonate }\end{array}$ & $\mathrm{Fe}$ & 26 & Direct Mixing & & $\begin{array}{l}\text { // magnetic field - } \\
\text { induced by solenoid } \\
(90 \mathrm{mT})\end{array}$ & $\phi=4 \% ; 1.4$ \\
\hline [19] & Water & Unknown & $\mathrm{Fe}_{3} \mathrm{O}_{4}$ & 7.5 & $\begin{array}{l}\text { Co- } \\
\text { precipitation }\end{array}$ & $\begin{array}{l}\text { Sine-Wave Vibro } \\
\text { Viscometer (SV- } \\
\text { 10) }\end{array}$ & $\begin{array}{l}\llcorner\text { magnetic field - } \\
\text { permanent magnet } \\
(30 \mathrm{mT})\end{array}$ & $\phi=5 \% ; 1.78$ \\
\hline \multirow[t]{2}{*}{ [36] } & \multirow[t]{2}{*}{ Water } & $\begin{array}{l}\text { Oleic Acid (activator); } \\
\text { PEG-4000 (surfactant) }\end{array}$ & \multirow[t]{2}{*}{$\mathrm{Fe}_{3} \mathrm{O}_{4}$} & \multirow[t]{2}{*}{$\sim 9-10 ; 23$} & $\begin{array}{l}\text { Co- } \\
\text { precipitation }\end{array}$ & \multirow{2}{*}{$\begin{array}{l}\text { Capillary Tube } \\
\text { Viscometer (= } \\
\text { Capillary } \\
\text { Rheometer) and } \\
\text { Rotating } \\
\text { Rheometer } \\
\text { (Brookfield LVDV } \\
\text { III+) }\end{array}$} & None & Unknown \\
\hline & & $\begin{array}{l}\text { Oleic Acid (activator); } \\
\text { PEG powder } \\
\text { (surfactant) }\end{array}$ & & & $\begin{array}{l}\text { Chemical } \\
\text { Precipitation + } \\
\text { Ball Milling }\end{array}$ & & None & Unknown \\
\hline [20] & Methanol & $\begin{array}{l}\text { Tetramethyl } \\
\text { ammonium hydroxide } \\
\text { (TMAH) }\end{array}$ & $\mathrm{Fe}_{3} \mathrm{O}_{4}$ & $5+/-0.2$ & $\begin{array}{l}\text { Co- } \\
\text { precipitation }\end{array}$ & $\begin{array}{l}\text { Dial reading } \\
\text { viscometer }\end{array}$ & L magnetic field & Unknown \\
\hline
\end{tabular}




\begin{tabular}{|c|c|c|c|c|c|c|c|c|}
\hline & & Oleic Acid & & & & $\begin{array}{l}\text { (Brookfield, } \\
\text { M/00-151) }\end{array}$ & & Unknown \\
\hline [8] & Kerosene & Oleic Acid & $\mathrm{Fe}_{3} \mathrm{O}_{4}$ & $\begin{array}{l}6-20 ; \\
\text { mean } \\
10.6\end{array}$ & $\begin{array}{l}\text { Co- } \\
\text { precipitation }\end{array}$ & $\begin{array}{l}\text { MCR300 } \\
\text { Rheometer } \\
\text { (Physica Anton } \\
\text { Paar GmbH) } \\
\text { using plate-plate } \\
\text { spindle (PP25- } \\
\text { MRD) }\end{array}$ & $\begin{array}{l}\text { // magnetic field - } \\
\text { from rheometer } \\
\text { (electromagnet) }\end{array}$ & Unknown \\
\hline \multirow[t]{2}{*}{ [21] } & $\begin{array}{l}\text { Synthetic } \\
\text { Ester Oil }\end{array}$ & APGW05 (Ferrotec) & $\begin{array}{l}\mathrm{Fe}_{3} \mathrm{O}_{4}+ \\
\mathrm{V}^{-} \\
\mathrm{Fe}_{2} \mathrm{O}_{3}\end{array}$ & Unknown & Unknown & \multirow[t]{2}{*}{$\begin{array}{l}\text { Parallel plate } \\
\text { Rheometer }\end{array}$} & \multirow[t]{2}{*}{$\begin{array}{l}\llcorner\text { magnetic field - } \\
\text { permanent magnet }\end{array}$} & Unknown \\
\hline & $\begin{array}{l}\text { Synthetic } \\
\text { Ester Oil }\end{array}$ & APGW010 (Ferrotec) & $\begin{array}{l}\mathrm{Fe}_{3} \mathrm{O}_{4}+ \\
\mathrm{Y}^{-} \\
\mathrm{Fe}_{2} \mathrm{O}_{3}\end{array}$ & Unknown & Unknown & & & Unknown \\
\hline
\end{tabular}


